\title{
Health, fairness and taxation
}

Citation for published version (APA):

Valletta, G. (2012). Health, fairness and taxation. METEOR, Maastricht University School of Business and Economics. METEOR Research Memorandum No. 017 https://doi.org/10.26481/umamet.2012017

Document status and date:

Published: 01/01/2012

DOI:

10.26481/umamet.2012017

Document Version:

Publisher's PDF, also known as Version of record

\section{Please check the document version of this publication:}

- A submitted manuscript is the version of the article upon submission and before peer-review. There can be important differences between the submitted version and the official published version of record.

People interested in the research are advised to contact the author for the final version of the publication, or visit the DOI to the publisher's website.

- The final author version and the galley proof are versions of the publication after peer review.

- The final published version features the final layout of the paper including the volume, issue and page numbers.

Link to publication

\footnotetext{
General rights rights.

- You may freely distribute the URL identifying the publication in the public portal. please follow below link for the End User Agreement:

www.umlib.nl/taverne-license

Take down policy

If you believe that this document breaches copyright please contact us at:

repository@maastrichtuniversity.nl

providing details and we will investigate your claim.
}

Copyright and moral rights for the publications made accessible in the public portal are retained by the authors and/or other copyright owners and it is a condition of accessing publications that users recognise and abide by the legal requirements associated with these

- Users may download and print one copy of any publication from the public portal for the purpose of private study or research.

- You may not further distribute the material or use it for any profit-making activity or commercial gain

If the publication is distributed under the terms of Article $25 \mathrm{fa}$ of the Dutch Copyright Act, indicated by the "Taverne" license above, 


\section{Maastricht University}

Giacomo Valletta

Health, Fairness and Taxation

$\mathrm{RM} / 12 / 017$

\section{METEOR}

Maastricht University School of Business and Economics

Maastricht Research School of Economics

of Technology and Organization

P.O. Box 616

NL-6200 MD Maastricht

The Netherlands 


\title{
HEALTH, FAIRNESS AND TAXATION
}

March 18, 2012

Giacomo Valletta ${ }^{\dagger}$

\begin{abstract}
We consider a model where agents differ in their preferences about consumption labor and health, in their (health-dependent) earning ability, and in their health disposition. We study the joint taxation of income and health expenditure, under incentive-compatibility constraints, on the basis of efficiency and fairness principles. The fairness principles we consider propose, on one side, to reduce inequalities deriving from factors that do not depend on individuals' responsibility. On the other side, redistribution should be precluded at least when all agents in the economy have equal physical characteristics. We construct, on the basis of such principles, a particular social welfare function. Then we give the explicit formula for the comparison of tax policies: we prove that a tax reform should always benefit agents with the worst earning ability and the worst health disposition first. Finally, at the bottom of the income distribution the optimal tax scheme should exhibit non-uniform tax rates over health expenditure and non-positive average marginal tax rates over income.

Keywords: Income tax, Health subsidies, Endogenous skills, Policy evaluation, Optimal tax, Fairness.

JEL classification: D63; H20.
\end{abstract}

\section{INTRODUCTION}

In this paper we study how certain ideas of fairness can affect the design of a tax system that encompasses labor income and health expenditure.

To address this issue we put forward a model where individuals differ in their health disposition (namely, they have to face unequal costs in order to be in good health) and in their healthdependent earning ability. Moreover, they have heterogeneous preferences over consumption, labor and health: they typically make different choices about their labor time and their health status.

A given level of health may be considered, at least to some extent, as the result of a responsible choice (that is, a given lifestyle may induce a given health status). However such a choice might entail a different (intrinsic) cost for different agents. This might be due to circumstances that are beyond their responsibility: differences in health disposition across agents may be due to genetic factors $^{1}$ or to the social background ${ }^{2}$.

Acknowledgments: I thank Claude d'Aspremont, Timos Athanasiou, Marc Fleurbaey, Marie-Louise Leroux, François Maniquet, Juan D. Moreno-Ternero, Pierre Pestieau, Erik Schokkaert, Fred Schroyen, the participants to workshops and conferences in Liege, Louvain La Neuve, Montreal, Padova and Pittsburgh, for their comments.

${ }^{\dagger}$ Maastricht University, Department of Economics (AE 1), Faculty of Economics and Business Administration, P.O. Box 616, NL-6200 MD Maastricht, the Netherlands. (mail: g.valletta@maastrichtuniversity.nl)

${ }^{1}$ Christensen et al. [11] shows that approximately a quarter of the variation in the liability to self-reported health and the number of hospitalizations could be attributed to genetic factors.

${ }^{2} \mathrm{~A}$ high socio-economic status is typically associated with better health and longer life, see for example Reid et al. [34], or Marmot el al. [30]. 
Unlike other commodities, health has an impact on the earning ability of agents. Typically an increase in health leads to an increase in productivity, which should be reflected in an increased wage $^{3}$. This means that agents' productivity is, at least to some extent, endogenous, since it depends on the choice of a certain health status ${ }^{4}$. However certain individuals might be more productive than others for any level of health. Such heterogeneity might be due to innate circumstances which do not lie within individual responsibility.

All these differences generate health and income inequalities. A part of such inequalities can be considered "legitimate" (Fleurbaey and Schokkaert[21]) since it is generated by causes that lie within individual responsibility while others are not.

In such a framework we study how to combine non-linear income tax with the subsidization (taxation) of health expenditure. More precisely, a tax policy is a function defining a transfer of income depending both on the level of earnings and on the health expenditure. So two individuals with the same earnings might be subject to a different taxation (for example, one is subsidized and the other is taxed) solely because of a different health expenditure (due to different health care needs).

We should stress immediately that, like in Fleurbaey [12] an ex-post viewpoint is adopted here in order to deal with uncertainty. Health insurance is often examined from the ex ante viewpoint ${ }^{5}$ and it is well known that private markets might fail to provide health insurance to some people having too high risks and this could justify public intervention. Here we are rather interested in the normative considerations that might lead eventually to transfer resources from agents with a good health disposition to agents with a bad disposition. The ex-post point of view does not disregard differences deriving from random events but it gathers them together with differences deriving from fixed characteristics.

In redistributing resources through a tax system the policy maker faces distortions due to the asymmetry of information. Such an efficiency loss is typically justified by the potential improvement in the fairness of the distribution of resources. We deal with this trade-off by constructing (axiomatically) a precise definition of social welfare that incorporates efficiency and fairness concerns. The first ethical principle we adopt aims at reducing inequalities deriving from factors that do not depend on individual responsibility. In our framework this amounts to defending inequality reduction between individuals who have equal preferences but differ in their (health-dependent) earning ability and in their health disposition. The second ethical principle is oriented toward the acceptance of inequalities deriving from a different exercise of individual responsibility: there should not be redistribution across individuals at least when they all have equal earning ability and health disposition but possibly different preferences. In such a case, income inequalities would just reflect free choices deriving from different preferences on an identical budget set, and such choices ought to be respected.

Such ethical principles ${ }^{6}$ (together with the Pareto principle) are embedded in axioms that are used to characterize a specific notion of social welfare. This notion of social welfare uses a specific index in order to measure individual well-being. Such an index is the lump-sum transfer that would leave an agent indifferent between her current bundle and being free to choose labor time and health expenditure from a hypothetical budget set where both earning ability and health disposition are equal to the average ones. This index does not require any other information

\footnotetext{
${ }^{3}$ For empirical evidence see, among others, Mushkin [31], Grossman and Benham [23], Luft [29].

${ }^{4}$ Clearly, for some agents this might not be true because it is "too costly" for them to have a good health status. In our model this amounts to say that they have a bad health disposition.

${ }^{5}$ See Blomqvist and Horn [4], Cremer and Pestieau [10], Rochet [35], among others.

${ }^{6}$ See Fleurbaey and Maniquet [16] and Fleurbaey [14] for a detailed survey of the topic.
} 
about individuals than their ordinal non-comparable preferences. Individual indices are finally aggregated using the leximin criterion.

The analysis of the design of the tax system (jointly with the health subsidies) for a population which is heterogeneous in more than one dimension is an extremely difficult task. Nonetheless we are able to provide a precise and simple criterion for the evaluation of tax policies. Different tax policies entail different social consequences and these are evaluated with the notion of social welfare we have defined. We are able to describe which part of the budget set modified by the tax policy should be the focus of the policy maker, and which modification of it leads to a social improvement. We prove that, when comparing two different tax policies, priority should always be given to the least skilled individuals with the worst health disposition. Interestingly this criterion can be used for the comparison of any pair of tax policies, no matter how far from the optimum, and little information about individual characteristics is needed for its application. In this sense, our criterion could provide a useful guide, for the policy maker, to asses reforms.

In spite of the heterogeneity of agents over three dimensions (health disposition, earning ability, preferences) we are also able to describe some relevant features of the optimal tax policy. The focus is on low income earners. They should optimally face non-uniform tax rates over health expenditure. Indeed, the consumption (net of health expenditure) granted to hardworking poor agents (unskilled agents who work full time) who decide to purchase health care (but eventually have a different health disposition) should be equalized. As a consequence, at the optimal tax scheme, hardworking poor agents with the highest health expenditure are those who should receive the highest subsidy (pay the lowest tax). Finally, within each sub-population defined by the health expenditure level, the taxation of low income earners is to some extent regressive. That is, for any level of health expenditure, the average marginal tax rate on income is non-positive and those who work full time are granted the greatest subsidy (i.e. the smallest tax).

The paper is organized as follows. Section 2 reviews the relevant literature. Section 3 introduces the model and the notation. Section 4 describes the requirements imposed on the social preferences. Section 5 deals with axiomatic derivation of social preferences. Section 6 proposes a way to compare different tax policies and describes some features of the optimal one. Section 7 concludes. The Appendix provides the proofs.

\section{Related Literature}

Several papers have already studied the joint taxation of income and health expenditure. Blomqvist and Horn [4], in a model where individuals differ in their (exogenous) labor productivity and in their probability of being ill, prove that subsidizing ill people (through lump-sum transfers) can be an effective complement to linear taxation for redistributive purposes. Rochet [35] and Henriet and Rochet [24] extend the analysis to a continuum of types and show that the existence of a negative relation between productivity and morbidity (the probability to become ill) is a necessary and sufficient condition for full public health insurance to be optimal ${ }^{7}$. Such a result is confirmed by Cremer and Pestieau [10] (who restrict their attention to a discrete distribution of types). In these papers bad health is used as an imperfect signal of an agent's ex ante risk of falling ill. Hence, covering people against such a risk by mean of a public health insurance is welfare improving. Jack [27] considers a model where agents face heterogeneous prices for health improvement and where their health status affects their earning ability. In such a framework health expenditure could be either subsidized or taxed depending on the correlation

\footnotetext{
${ }^{7}$ The latter paper in particular explains the positive correlation between marginal tax rates (used as a proxy for social preferences toward redistribution) across different countries and the extent of public provision of health insurance.
} 
between health status and income, and the elasticities of demand for health care and supply of labor.

All these papers have focused on social objectives defined in terms of welfarist (typically utilitarian) social welfare functions, based on interpersonal comparisons of utility. This means that the tension toward redistribution is determined by some degree of concavity in the utilitarian objective. But this also means that there is not an explicit analysis concerning the way fairness affects the shape of the social welfare function. Moreover, as in many other contributions on income taxation (that do not necessarily involve health expenditure), individual preferences are usually assumed to be homogeneous: this makes the exercise of defining the social welfare function easier but undoubtedly diminishes the realism of the model. A common result of this approach is that marginal tax rates that are everywhere positive. This result still holds in situations where the maximin criterion is used. Using the fact that under maximin the shape of the optimal tax scheme does no longer depend on the skill distribution, Boadway and Jacquet [5] provide minimal conditions for the marginal tax rate to be not only positive but also decreasing throughout the whole skill distribution.

Things become considerably more complex if individual preferences are assumed to be heterogeneous. Several authors (Boadway, Marchand, Pestieau and Racionero [6], Choné and Laroque [8] [9], Jacquet and Van de gaer [28], Saez [37]) have examined optimal taxation under the assumption that agents may be heterogeneous in two dimensions, their consumption-leisure preferences and their earning ability (these papers exclusively deal with income taxation, health is not part of the analysis and agents' productivities are exogenous). They all face the common difficulty that summing utility levels of agents with different preferences requires an "arbitrary" cardinalization of utility functions. Moreover, as explicitly mentioned by Jacquet and Van de gaer [28], with double heterogeneity, traditional welfarist criteria (including utilitarianism) might lead to unappealing policy recommendations in the sense that they fail to compensate agents for inequalities deriving from characteristics they cannot be held responsible for. Moreover, using social preferences of the utilitarian type when agents have heterogeneous preferences might also lead to policy recommendations that fail the second ethical criterion we put forward. Indeed, if agents' utilities have different weights then the optimal policy might require some redistribution even if all agents have equal earning ability (and, eventually, equal health disposition).

Our result of a non-positive average marginal rate among low income earners, which is otherwise quite unusual, also relates to this strand of literature. Adding a further dimension of heterogeneity might in fact lead to negative marginal tax rates at the bottom of the income distribution (see in particular (Choné and Laroque [9], Boadway, Marchand, Pestieau and Racionero [6]). Again, in a purely utilitarian framework, this depends on the particular social weights given to certain kinds of individual preferences (we come back on this point at the end of section 5).

On the contrary, we characterize axiomatically a precise definition of social welfare for an heterogeneous population. The axioms used to perform such an exercise are derived from fairness criteria that are specific to the problem we are dealing with. Interestingly, also the relative weight of agents having different preferences does not need to be determined by assumption, but it is singled out by the fairness conditions we impose. Such a methodology was introduced by Fleurbaey and Maniquet [15] and has been used for the evaluation of public policies in several frameworks already ${ }^{8}$. We mostly build on Fleurbaey [12] and Valletta [39]. The former one, in particular, studies how to define social objectives for the allocation of health and consumption in a model where individuals have different preferences over health and consumption, different

\footnotetext{
${ }^{8} \mathrm{~A}$ wide and detailed description of this methodology and its possible applications is provided by Fleurbaey and Maniquet [17].
} 
earning ability, and different health disposition but they offer labor inelastically. This means that the distortions that social security contributions might cause to the price of production factors, especially labor, cannot be taken into account. We extend the analysis by adding labor as a new dimension and we propose an alternative social objective ${ }^{9}$. On the other hand, Fleurbaey and Maniquet [19], [20] propose an array of social preferences (over the allocation of consumption and labor) and an array of criteria for the welfare evaluation of tax policies based on normative criteria that have to be thought anew if a further dimension like health is added: they work in a framework where the earning ability of agents is exogenous so that agents are not responsible for it. Here agents can affect their marginal productivity, to some extent, with the choice of their health status. A common feature of the (optimal) tax policies they propose is that hardworking-poor agents should be granted the smallest tax burden in the whole population. But still, imposing the same tax policy to individuals with different health expenditure might lead, de facto, to income inequalities that are particularly undesirable among low income earners. Indeed, the main reason it might be desirable to integrate health care expenditure into a redistributive tax system is that even people with the same earning ability might have to face very different health-care costs.

Finally, our paper also relates to the literature on commodity taxation. In their seminal contribution Atkinson and Stiglitz [3] showed that within a population of individuals who differ only in their labor productivity, if preferences are separable between labor and consumption of other goods, then commodity taxation cannot increase welfare above the level obtained with an optimal income tax alone. Many studies have examined the robustness of this result (see Boadway and Pestieau [7] for an overview). Fleurbaey [13], in particular, has proven (using an approach similar to ours) that in presence of heterogeneous preferences and non-linear commodity taxation, the hardworking-poor agents should be submitted to a uniform or null commodity tax. The fact that, in our paper, agents have to face unequal costs in order to be in good health leads to a quite different result: the optimal tax clearly exhibits a non-uniform tax rate on health expenditure across low-income earners.

\section{The Model}

We consider a set of economies with a finite set of agents $N \subset \mathbb{N}$. There are three goods: consumption, labor and health. A bundle, for agent $i \in N$, is a triple $z_{i}=\left(c_{i}, l_{i}, h_{i}\right)$, where $c_{i}$ is consumption, $l_{i}$ is labor, and $h_{i}$ is health status. In particular, $c_{i} \in \mathbb{R}_{+}$will be interpreted here as the expenditure on ordinary consumption goods, excluding health expenditure (medical treatments and drugs). As usual for this kind of analysis $l_{i} \in[0,1]$. For the sake of simplicity we assume that the choice of health is dichotomous. Each individual can either decide to keep a basic level of health (for simplicity we normalize such an amount to zero) or she can decide to face the necessary costs in order to be healthy (that is, $h=1$ ). A more general model, describing health as a multidimensional and continuous variable would be certainly more realistic and most of the results, in principle, would still hold. We think this very stylized description of reality better serves the purpose of the paper since it allows to describe with much more precision which

\footnotetext{
${ }^{9}$ Fleurbaey's paper in fact proposes to maximin the lowest level of full health equivalent consumption occurring in society. The full health equivalent consumption is the sincere answer to the question: how much consumption would you need to be indifferent between your current bundle and being fully healthy? One could in fact think of applying the maximin criterion to the full-health leisure equivalent incomes, namely, the amount of income that would be sufficient for an individual if her health problems disappeared and she no longer had to work. As it will be clearer later this might lead to some ambiguous redistributive effects. In particular, redistribution might go, from the hardworking poor to the lazy-rich (a skilled agent who decides to work little). Moreover such a way to rank alternatives might lead to redistribution even in a situation where all agents are equally productive and have the same health disposition.
} 
direction redistribution should take among certain groups of agents. An allocation describes each agent's bundle and will be denoted by $z=\left(z_{i}\right)_{i \in N}{ }^{10}$. Let $Z$ denote the set of all allocations.

Agents have three characteristics: their preferences, their earning ability and their health disposition.

For each $i \in N$, preferences are denoted $R_{i}$ and $z_{i}^{\prime} R_{i} z_{i}$ (resp. $\left.z_{i}^{\prime} P_{i} z_{i}, z_{i}^{\prime} I_{i} z_{i}\right)$ means that bundle $z_{i}^{\prime}$ is weakly preferred (resp. strictly preferred, indifferent) to bundle $z_{i}$. Let $R=\left(R_{i}\right)_{i \in N}$ denote the population's profile of preferences. We restrict our attention to preferences which are continuous, strictly monotonic (non-decreasing in $c_{i}$ and $h_{i}$, non-increasing in $l_{i}$ ) and convex.

We assume that the marginal productivity of labor (measured in consumption units) of each agent is increasing in health. That is, for each $i \in N, w_{i}(0)<w_{i}(1)$. We also assume that agents might be more or less productive because of a different innate ability. To keep things simple we assume that there are only two types of agents: unskilled agents and skilled agents so that, for each $i \in N$, either $w_{i}(h)=w^{u}(h)$ or $w_{i}(h)=w^{s}(h)$, with $w^{s}(h)=\gamma w^{u}(h)$ for each $h \in\{0,1\}$ and $\gamma>1 .^{11}$ Let $w()=.\left(w_{i}(.)\right)_{i \in N}$ denote the population profile of earning ability mappings.

Each agent is also characterized by a mapping describing the amount of medical expenses necessary to bring her to the health status $h$. We assume there are only two types of agents: agents with a good health disposition and agents with a bad health disposition. So, for each $i \in N$, either

or

$$
m_{i}\left(h_{i}\right)=m^{g}\left(h_{i}\right)=\left\{\begin{array}{lll}
0 & \text { if } & h_{i}=0 \\
m^{-} & \text {if } & h_{i}=1
\end{array}\right.
$$

$$
m_{i}\left(h_{i}\right)=m^{b}\left(h_{i}\right)=\left\{\begin{array}{lll}
0 & \text { if } h_{i}=0 \\
m^{+} & \text {if } h_{i}=1
\end{array}\right.
$$

with $m^{-}<m^{+}$. Such a mapping captures all exogenous factors that determine the medical costs, including not only purely medical features (genetic factors, sensitivity to drugs, congenital diseases) but also social and economic characteristics which influence each agent's health. Let $M=\left\{0, m^{-}, m^{+}\right\}$denote the set of all possible health expenditure levels and $m()=.\left(m_{i}(.)\right)_{i \in N}$ the population profile of health disposition mappings.

The choice of only two types of agents, both for the description of earning ability and health disposition may look too restrictive. Most of the results that follow would still hold in an environment involving many types but it would be impossible to devise sharp conclusions about the direction redistribution should take.

An economy is denoted by $e=(R, w(),. m()$.$) . Let \mathcal{D}$ denote the set of economies complying with our assumptions.

An allocation is feasible if

$$
\sum_{i=1}^{|N|} c_{i}+\sum_{i=1}^{|N|} m_{i}\left(h_{i}\right) \leq \sum_{i=1}^{|N|} w_{i}\left(h_{i}\right) l_{i} .
$$

In absence of redistribution, the budget set of each agent is equal to the possible combinations of consumption, labor and health that are attainable for her, given her earning ability and her health disposition. So, for each $i \in N$,

$$
B^{l f}\left(w_{i}(.), m_{i}(.)\right)=\left\{\left(c_{i}, l_{i}, h_{i}\right) \in \mathbb{R}_{+} \times[0,1] \times\{0,1\} \mid c_{i}+m_{i}\left(h_{i}\right) \leq w_{i}\left(h_{i}\right) l_{i}\right\} .
$$

\footnotetext{
${ }^{10}$ Given a list of objects $a=\left(a_{i}\right)_{i \in N}, a_{-i}$ will denote the list $\left(a_{1}, \ldots, a_{i-1}, a_{i+1}, \ldots, a_{N}\right)$ and, more in general, given some $S \subseteq N, a_{-S}$ will denote the original list excluding all the elements belonging to $S$.

${ }^{11}$ Notice that such a framework is general enough to describe a situation where eventually an unskilled but healthy agent has a higher marginal productivity than a skilled but unhealthy one, that is, $w^{u}(1)>w^{s}(0)$.
} 
A laissez - faire allocation $z^{l f}$ is such that for each $i \in N, z_{i}^{l f}$ is the best for $R_{i}$ over $B^{l f}\left(w_{i}(),. m_{i}().\right)$. An agent $i \in N$ is said to be taxed (resp., subsidized) when $c_{i}+m_{i}\left(h_{i}\right)<w_{i}\left(h_{i}\right) l_{i}$ (resp. $\left.c_{i}+m_{i}\left(h_{i}\right)>w_{i}\left(h_{i}\right) l_{i}\right)$. In the first best context income redistribution could be performed through lump-sum transfers. Such transfers will be denoted, for each $i \in N$, as $t_{i} \in \mathbb{R}$. This means that agent $i$ 's first-best budget set is then:

$$
B\left(t_{i}, w_{i}(.), m_{i}(.)\right)=\left\{\left(c_{i}, l_{i}, h_{i}\right) \in \mathbb{R}_{+} \times[0,1] \times\{0,1\} \mid c_{i}+m_{i}\left(h_{i}\right) \leq t_{i}+w_{i}\left(h_{i}\right) l_{i}\right\} .
$$

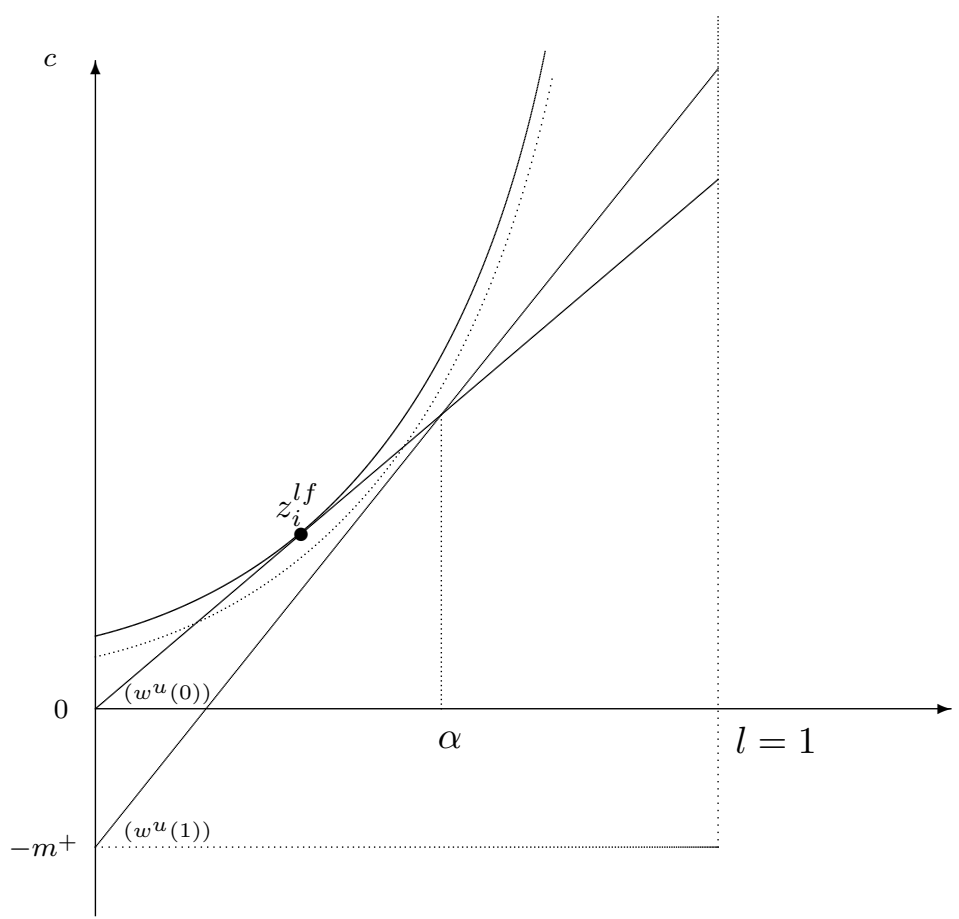

FiguRE 1. The main features of the model.

It is important to notice that our model allows to capture the fact that agents might choose to be in good health $(h=1)$ just because they care about their health condition, because they care about consumption (a good health status increases her earning ability, agents that like to consume a lot are more likely to be healthy than others), or both.

Figure 1 and 2 describe this fact with an example. For some $i \in N$, let $w_{i}()=.w^{u}($.$) and$ $m_{i}()=.m^{b}($.$) . The straight lines depicted into the figures represent i$ 's budget set. If she chooses $h_{i}=0$ (resp. $\left.h_{i}=1\right)$ then her marginal productivity is $w^{u}(0)$ (resp. $w^{u}(1)$ ), this means she can choose any of the pairs $(c, l)$ along the straight line with origin in $(0,0)$ (resp. $\left.\left(0,-m^{+}\right)\right)$and slope equal to $w^{u}(0)$ (resp. $w^{u}(1)$ ). Such a choice depends on her preferences ${ }^{12}$. Indeed, if her preferences are as in figure 1 , she will choose a bundle $z_{i}^{l f}$ such that $h_{i}=0$. This means that the tangency point between her indifference curve and her budget set is on the line with slope $w^{u}(0)$ and origin in $0^{13}$. Figure 2 represents a different choice due to different preferences. Agent $i$ decides to pay the amount $m^{+}$in order to be healthy and her productivity is increased from $w^{u}(0)$ to $w^{u}(1)$ so that she can also enjoy an higher consumption (agents willing to work more than $\alpha$

\footnotetext{
${ }^{12}$ Notice that, for any given bundle $z_{i} \in Z$ the darker indifference curve depicts all the pairs $(c, l)$ such that $(c, l, 0) I_{i}\left(c_{i}, l_{i}, h_{i}\right)$. The dotted curve depicts all the pairs $(c, l)$ such that $(c, l, 1) I_{i}\left(c_{i}, l_{i}, h_{i}\right)$.

${ }^{13}$ Notice that the dotted part of the indifference curve lies always above the straight line with origin in $\left(0,-m^{+}\right)$ and slope $w^{u}(1)$.
} 


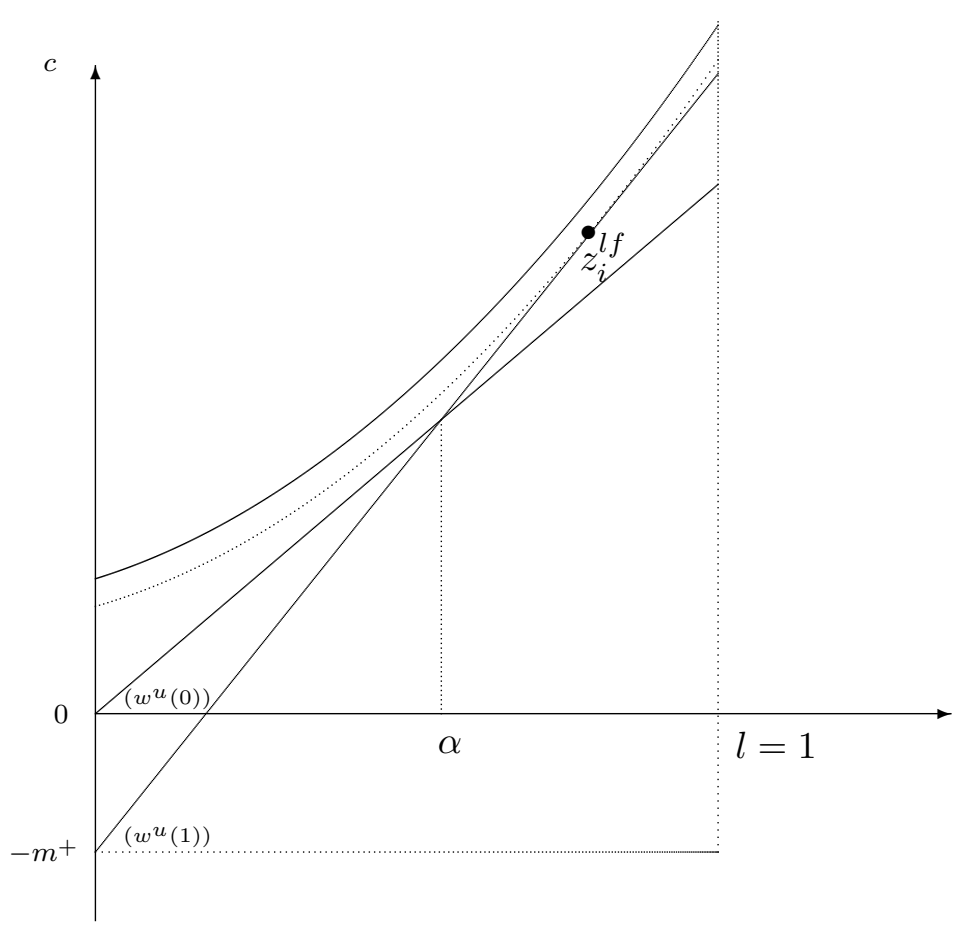

FiguRE 2. The main features of the model.

would anyway decide to be in good health because this gives them, everything being equal, more consumption). This means that she is choosing some pair $(c, l)$ on the line with slope $w^{u}(1)$ and origin in $-m^{+}$. It might also be the case that the amount $m^{+}$and the increase in productivity are such that the line with slope $w^{u}(1)$ and origin in $-m^{+}$lies always below the line with origin in 0 and slope $w^{u}(0)$. In this case agents would decide to be in good health only because of their particular concern about health. Notice finally, that changing the relative distance between the two straight lines (by mean, for example, of a subsidy on health expenditure) might obviously change the agent's choice about her health status.

The first problem addressed here is the definition of social preferences over allocations. Social preferences will allow us to compare allocations in terms of fairness and efficiency. They will be formalized as a complete ordering over all the (feasible and not feasible) allocations and they will be denoted by $\widetilde{R}$ for the weak preferences, with related strict preferences $\widetilde{P}$ and indifference $\widetilde{I}$. In other words, $z^{\prime} \widetilde{R} z$ means that the allocation $z^{\prime}$ is (socially) at least as good as $z, z^{\prime} \widetilde{P} z$ means that it is strictly better, and $z^{\prime} \widetilde{I} z$ that they are equivalent. The problem is to define social preferences for all cases that may occur. Formally, a social ordering function (SOF) is a mapping from the set of economies to the set of complete orderings over allocations. So, for each $e \in \mathcal{D}$, we write $\widetilde{R}(e), \widetilde{P}(e)$, and $\widetilde{I}(e)$ in order to express the fact that particular social preferences are specific to the economy $e \in \mathcal{D}$.

\section{FAirness ReQuirements}

This section introduces the requirements that we will impose on social preferences. Such requirements are specific to our framework. That is, they focus on some key aspects of the classical debate about labor income taxation. On the one hand, the need for redistribution comes from differences in circumstances that are beyond individual's responsibility. In our framework this amount to say that inequalities deriving solely from someone's health disposition or someone's 
innate ability are not acceptable. Assume there are two agents, $i$ and $j$, with equal preferences but (possibly) different health disposition mappings and different innate abilities. Assume also that, at a given allocation, they have the same quantity of labor and the same health status but agent $i$ can consume strictly more than agent $j$. Clearly, reducing agent $i$ 's consumption by a given amount and augmenting agent $j$ 's consumption by the same amount (with still $c_{i}>c_{j}$ ) should lead to a social improvement according to the above ethical goal. Otherwise, assume that, at a given allocation, they still have the same quantity of labor, the same health condition and agent $i$ can consume strictly more than agent $j$. Consider the allocation obtained just by permuting their respective levels of consumption. There is no reason why society should prefer one of the two allocations: agents with the same responsibility characteristics (namely, with equal preferences) should be treated anonymously.

Equal Well-being for Equal Preferences For all $e \in \mathcal{D}, z, z^{\prime} \in Z$, if there exist $i, j \in N$ and some $\Delta>0$, such that $R_{i}=R_{j}, l_{i}=l_{j}=l_{i}^{\prime}=l_{j}^{\prime}, h_{i}=h_{j}=h_{i}^{\prime}=h_{j}^{\prime}$ with $z_{k}=z_{k}^{\prime}$ for all $k \neq i, j$

then $z^{\prime} \widetilde{P}(e) z$; if otherwise

$$
c_{i}-\Delta=c_{i}^{\prime}>c_{j}^{\prime}=c_{j}+\Delta
$$

$$
c_{i}^{\prime}=c_{j} \text { and } c_{i}=c_{j}^{\prime}
$$

then $z^{\prime} \widetilde{I}(e) z$.

If compared to previous contributions (Fleurbaey and Maniquet [19] [20]), our richer model allows us to refine the normative analysis about the way personal responsibility relates to unequal achievements. Indeed, one key ethical consequence of this axiom is that agents are partially responsible for (the level of) their marginal productivity since they can, in part, affect it by changing their health status. For example, an unhealthy agent is compensated for her lack of productivity as long as she is compared with another unhealthy agent with a better innate ability. On the contrary she is not compensated for her lack of productivity if she is compared with an agent who has the same earning ability mapping but who has chosen to increase her marginal productivity by being healthy.

Redistribution should anyway have a limit: inequalities solely due to different choices might be acceptable since individuals should, at least to some extent, be held responsible for their goals. If all agents had the same health disposition mapping and the same earning ability mapping then they should be let free to choose a different amount of labor, a different health condition and hence, indirectly, a different productivity. The differences in consumption eventually deriving from such choices would be exclusively due to their differences in preferences. In our view there is nothing objectionable about such inequalities or, to put it differently, society should treat neutrally individual preferences and choices. The idea is that, at least when all agents have the same circumstances, redistribution should not depend on preferences. This clearly pushes in the direction of reducing the inequality of budgets, in particular, the inequality in lump-sum transfers.

Uniform Circumstances Neutrality: For all $e \in \mathcal{D}, z, z^{\prime} \in Z$, if for all $i, j \in N, w_{i}()=.w_{j}($.$) ,$ $m_{i}()=.m_{j}($.$) , and if there exist m, n \in N$ and some $\Delta>0$ such that, $\left.z_{m} \in \max \right|_{R_{m}} B\left(t_{m}\right.$, $\left.w_{m}(),. m_{m}().\right),\left.z_{m}^{\prime} \in \max \right|_{R_{m}} B\left(t_{m}^{\prime}, w_{m}(),. m_{m}().\right),\left.z_{n} \in \max \right|_{R_{n}} B\left(t_{n}, w_{n}(),. m_{n}().\right),\left.z_{n}^{\prime} \in \max \right|_{R_{n}}$ $B\left(t_{n}^{\prime}, w_{n}(),. m_{n}().\right)$, with $z_{k}=z_{k}^{\prime}$ for all $k \neq m, n$,

$$
t_{m}-\Delta=t_{m}^{\prime}>t_{n}^{\prime}=t_{n}+\Delta
$$

then $z^{\prime} \widetilde{P}(e) z$; if otherwise 
then $z^{\prime} \widetilde{I}(e) z$.

$$
t_{m}^{\prime}=t_{n} \text { and } t_{m}=t_{n}^{\prime}
$$

Two comments are at stake. First, this requirement implies that the laissez - faire allocation (i.e., no redistribution) should be the social optimum in the particular case of uniform earning ability and uniform health disposition. Second, both the requirements rely on the assumption that agents are responsible for their preferences and this is not free of controversy. For example Roemer [36] has argued that individuals should be held responsible only for what lies strictly within their control. According to this definition individual preferences do not necessarily belong to the domain of characteristics an individual should be held responsible for. For an extensive discussion about the compensation-responsibility cut see Fleurbaey [14].

The remaining requirements are basic conditions derived from the social choice literature. First, we want to take into account efficiency. We impose the standard Pareto condition on the social ordering function so that it will never lead to the selection of allocations that are inefficient.

Strong Pareto: For all $e \in \mathcal{D}, z, z^{\prime} \in Z$ if, for all $i \in N, z_{i}^{\prime} R_{i} z_{i}$ then $z^{\prime} \widetilde{R}(e) z$. If moreover, for some $j \in N, z_{j}^{\prime} P_{j} z_{j}$ then $z^{\prime} \widetilde{P}(e) z$.

Second, we introduce a condition that, like Arrow's condition of independence of irrelevant alternatives [1], limits the amount of information about individual preferences that may be used in the comparison of two allocations ${ }^{14}$. In line with Hansson [26], Pazner [32] and Fleurbaey and Maniquet [19] we propose a weaker requirement still consistent with the idea that as little information as possible should be used to build social preferences. Indeed we require social preferences over two allocations to depend only on individual indifference curves at these two allocations.

Independence: For all $z, z^{\prime} \in Z, e, e^{\prime} \in \mathcal{D}$, with $e=(R, w, m)$ and $e^{\prime}=\left(R^{\prime}, w, m\right)$, if for all $i \in N$ and $q \in Z$,

$$
\begin{aligned}
& z_{i} I_{i} q \Longleftrightarrow z_{i} I_{i}^{\prime} q \\
& z_{i}^{\prime} I_{i} q \Longleftrightarrow z_{i}^{\prime} I_{i}^{\prime} q
\end{aligned}
$$

then

$$
z^{\prime} \widetilde{R}(e) z \Longleftrightarrow z^{\prime} \widetilde{R}\left(e^{\prime}\right) z
$$

Third, we introduce a robustness condition following the idea that a social ordering function should provide similar solutions to similar problems. More precisely, adding or removing agents who receive the same bundle in two different allocations should not modify the social ordering ${ }^{15}$. As it will be clearer in the next section, there is some tension between this condition, if considered in its full force, and Uniform Circumstances Neutrality. This is why we propose a weaker version of it that applies only to specific sub-populations: for any $S \subseteq N$ let $\bar{m}_{S}()=.\frac{1}{|S|} \sum_{j \in S} m_{j}($.

\footnotetext{
${ }^{14}$ Arrow's condition requires social preferences over two allocations to depend only on individual preferences over these two allocations. Fleurbaey and Maniquet [15], and Fleurbaey, Suzumura and Tadenuma [22], have argued that such an informational requirement is excessively strong, especially in an economic environment like ours.

${ }^{15}$ This axiom was introduced by Fleurbaey and Maniquet [15] and it is reminiscent of the Separability condition, quite familiar in social choice (d'Aspremont and Gevers [2]), and of the Consistency condition, widely used in the theory of fair allocation (see Thomson [38]), except that it does not require to delete the resources consumed by the removed agents from the social endowment.
} 
and $\bar{w}_{S}()=.\frac{1}{|S|} \sum_{j \in S} w_{j}($.$) denote, respectively, the average health disposition mapping and the$ average earning ability mapping within the group $S$. For the ease of notation let $\bar{m}_{N}()=.\bar{m}($. and $\bar{w}_{N}()=.\bar{w}($.$) .$

Separation: For all $e \in \mathcal{D}$ and for all $z, z^{\prime} \in Z$, if there is $S \subseteq N$ such that $\bar{m}_{S}()=.\bar{m}($.$) ,$ $\bar{w}_{S}()=.\bar{w}($.$) and, for all i \in S, z_{i}=z_{i}^{\prime}$ then

$$
z^{\prime} \widetilde{R}(e) z \Longleftrightarrow z_{-S}^{\prime} \widetilde{R}\left(R_{-S}, w_{-S}(.), m_{-S}(.)\right) z_{-S} .
$$

\section{Social Preferences}

The fairness conditions introduced above do not convey, per se, a strong aversion to inequality. Nevertheless, combining together the requirements we have mentioned, entails an infinite aversion to inequality and forces social preferences to rely on the leximin criterion ${ }^{16}$. Let $\geq_{\text {lex }}$ denote the usual leximin ordering of $\mathbb{R}^{N}$ : for any $v, v^{\prime} \in \mathbb{R}^{N}, v^{\prime} \geq_{l e x} v$ if and only if the smallest coordinate of $v^{\prime}$ is greater than the smallest coordinate of $v$ or they are equal but the second smallest coordinate of $v^{\prime}$ is greater than the second smallest coordinate of $v$ and so on. Moreover, the leximin criterion needs to be applied to a precise evaluation of individual situations that is also singled out by the axioms we propose. Let us first define the notion of implicit transfer associated with an agent's indifference curve, a hypothetical health disposition $\bar{m}($.$) , and a hypothetical earning ability \bar{w}($.$) .$ It is the lump-sum transfer that would leave the agent indifferent between her current bundle and being free to choose labor time and health expenditure from a hypothetical budget set where both earning ability and health disposition are equal to the average ones, formally

$$
\operatorname{IT}\left(z_{i}, \bar{w}(.), \bar{m}(.), R_{i}\right)=\left.t \Leftrightarrow z_{i} I_{i} \max \right|_{R_{i}} B(t, \bar{w}(.), \bar{m}(.)) .
$$

This expression (we will also use the shorter notation $I T_{i}\left(z_{i}\right)$ ), viewed as a function of $z_{i}$, corresponds to a particular (money-metric) utility function. This measure of individual well-being does not require any information about individuals' subjective utility. It relies in fact only on ordinal non-comparable preferences about consumption, labor and health. Such indices are then aggregated in the following way.

Average Circumstances Egalitarian Equivalent Leximin (ACEE). For all $e \in \mathcal{D}, z, z^{\prime} \in Z$,

$$
z^{\prime} \widetilde{R}(e) z \Leftrightarrow\left(I T\left(z_{i}^{\prime}, \bar{w}(.), \bar{m}(.), R_{i}\right)\right)_{i \in N} \geq_{\text {lex }}\left(I T\left(z_{i}, \bar{w}(.), \bar{m}(.), R_{i}\right)\right)_{i \in N} .
$$

Such social preferences give priority to agents with the lowest $I T_{i}\left(z_{i}\right)$. Moreover, since $I T_{i}\left(z_{i}\right)$ is a particular representation of individual preferences, such a way to rank alternatives satisfies Strong Pareto.

Theorem 1: On the domain $\mathcal{D}$ a social ordering function satisfies Strong Pareto, Equal Wellbeing for Equal Preferences, Uniform Circumstances Neutrality, Independence and Separation, if and only if it is an Average Circumstances Egalitarian Equivalent Leximin function.

The basic idea is that if all agents had the same health disposition and the same earning ability it would be nice to reduce inequalities in implicit transfers. Indeed, we put ourselves in the counterfactual situation where these functions are the same for all the agents and, in particular, they are equal to the average of the actual functions. In such a situation all agents would have a budget set shaped in the same way, independently of their preferences. The agents'

\footnotetext{
${ }^{16}$ This is a well-established fact in the social choice literature, see Fleurbaey and Maniquet [17].
} 


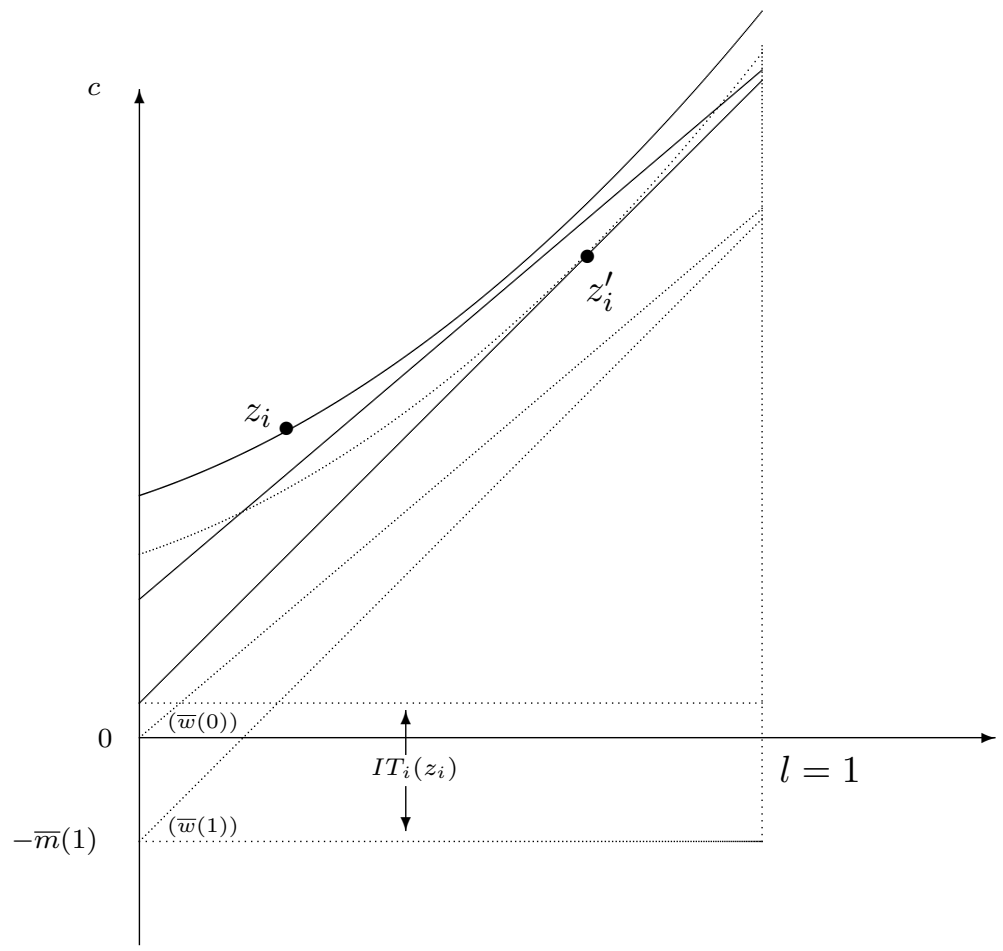

Figure 3. The IT well-being index

earning ability and health disposition are not the same in reality, but the social objective pushes toward an allocation that would equalize well-being (according to the particular metric we are using) in an ideal equal disposition, equal earning ability situation. The reader should also notice that for the characterization of the social preferences we only need to use the second part of Uniform Circumstances Neutrality.

The notion of implicit transfer is illustrated in figure 3. The two dotted straight lines represent $B(0, \bar{w}(),. \bar{m}()$.$) . This is a hypothetical budget set where circumstances are equal to the average$ ones. That is, health expenditure could be either 0 or $\bar{m}(1)$ and marginal productivity could be either $\bar{w}(0)$ or $\bar{w}(1)$. Consider, for some $i \in N$, the bundle $z_{i}$ (where, for example, $h_{i}=0$ ), what is the measure of $I T_{i}\left(z_{i}\right)$ ? We just have to slide upward the whole ${ }^{17}$ hypothetical budget set until one of the two lines touches (look at the two dark straight lines in the figure) one of the two curves that constitute the indifference set of agent $i$ at $z_{i}$. The manifold touches the indifference set in correspondence of the point $z_{i}^{\prime}$. So, agent $i$ is indifferent between the bundle she actually receives, $z_{i}$, and the bundle she would choose from the budget set $B\left(I T_{i}\left(z_{i}\right), \bar{w}(),. \bar{m}().\right)$.

It is easy to check that the ACEE social ordering function satisfies Equal Well-being for Equal Preferences and Uniform Circumstances Neutrality. As far as the former axiom is concerned, whether an agent $i$ 's characteristics, $m_{i}($.$) and w_{i}($.$) , are actually equal to \bar{m}($.$) and \bar{w}($.$) or not$ is, in essence, irrelevant. What matters is her level of satisfaction. Therefore, assessing her relative satisfaction by measuring her implicit transfer in terms of $\bar{m}($.$) and \bar{w}($.$) and trying to$ equalize (permuting) these values complies with this axiom. Regarding the latter axiom, if we were facing the situation where all the agents have identical earning ability and health disposition, then the hypothetical budget set of each agent would coincide with the real one. So, equalizing

\footnotetext{
${ }^{17}$ We have to slide the two dotted straight lines upward and, in doing so, we have to keep their vertical distance at the origin unchanged.
} 
(permuting) the implicit transfers across agents amounts to equalizing (permuting) their actual lump-sum transfers.

Our axiomatization share some similarities with Fleurbaey and Maniquet [19], [20]. The former contribution proposes a social ordering function that, compared to ours, is less responsibility minded. A weakening of the separability condition allows us to use a stronger responsibility requirement. The latter contribution proposes a family of social ordering functions where the choice of the reference parameters is arbitrary (and even if all agents had equal circumstances it would still require some redistribution). It is important to stress that here the choice of the average earning ability and of the average health disposition as reference mappings is actually dictated by the axioms we have chosen. It is clear that the way we have formulated the separability condition (that is, the fact that it only applies to specific sub-populations of individuals) plays a crucial role in the determination of the reference earning ability and of the reference health disposition. However a more general formulation of the axiom would conflict with Uniform Circumstances Neutrality. Indeed, the latter axiom implies that the choice of the reference circumstances needs to be profile dependent. That is, if all the agents in the economy had the same health disposition and the same earning ability then, necessarily, the reference circumstances should coincide with the real ones. This implies that the utility representation has to depend on the particular profile of circumstances in a given economy. Hence, we need to weaken the separability condition in such a way that, adding or removing agents who receive the same transfer in two different allocations, does not change the utility representation we are using (because this might modify the social ordering). This is achieved by applying the separability requirement only to sub-populations whose average health disposition and whose average earning ability is equal to the population's average. Removing them does not change $\bar{m}($.$) and \bar{w}($.$) so that also the function \operatorname{IT}($.$) does not$ change. We did have some degrees of freedom in the choice of our metric but the other options did not seem very appealing. For example, we could have used the geometric mean instead of the arithmetic one. This would have led to a different, less interesting, utility representation. Indeed, using the average circumstances as reference ones is quite intuitive since, ideally, all agents are entitled to an equal split of the overall production possibility set ${ }^{18}$.

\section{TAXATION}

In this section we use the social preferences described before in order to derive a precise and simple criterion for the comparison of tax policies given the social consequences they determine. We also analyze the features of the optimal tax policy.

We assume that only earned income, $y_{i}=w_{i}\left(h_{i}\right) l_{i}$, is observable. We also assume that health expenditure is observable, $m_{i}=m_{i}\left(h_{i}\right)$, but not the actual level of health. A tax policy is a function defining a transfer of income depending on the level of earnings and on the health expenditure. Namely, redistribution is made via a tax function $T(y, m)$ (the tax turns into a subsidy when $T(y, m)<0)$. Indeed in many countries, one agent's income tax does depend on more than her earnings. Often health expenditure is to some extent deductible. Hence it is also an argument of the tax function. Moreover health expenditure is readily observable whereas checking the actual health status of each agent is typically too expansive for the policy maker.

Individuals are free to choose their labor time and their health status in the budget set modified by the tax function. The government knows the distribution of types in the population but ignores the characteristics of any particular agent. Under the tax policy $T$, agent's $i$ budget set is

\footnotetext{
${ }^{18}$ The characterization of all the possible utility representations compatible with Uniform Circumstances Neutrality and some Separation condition is left to future research.
} 


$$
c_{i} \leq w_{i}\left(h_{i}\right) l_{i}-m_{i}\left(h_{i}\right)-T\left(w_{i}\left(h_{i}\right) l_{i}, m_{i}\left(h_{i}\right)\right) .
$$

In what follows we will focus on the consumption, earnings, health expenditure space where agent's $i$ budget set becomes

$$
c_{i} \leq y_{i}-m_{i}-T\left(y_{i}, m_{i}\right)
$$

For each $m \in M$ let $h_{i}(m)=m_{i}^{-1}(m)$ denote the health status that can be associated with the health expenditure $m$. This clearly depends on the health disposition of each agent. So, for each $i \in N$ either

or

$$
h_{i}(m)=\left(m^{g}\right)^{-1}(m)= \begin{cases}0 & \text { if } m<m^{-} \\ 1 & \text { if } m \geq m^{-}\end{cases}
$$

$$
h_{i}(m)=\left(m^{b}\right)^{-1}(m)= \begin{cases}0 & \text { if } m<m^{+} \\ 1 & \text { if } m \geq m^{+}\end{cases}
$$

Notice that an agent with a good health disposition can always mimic an agent with a bad health disposition ${ }^{19}$, since $\left(m^{g}\right)^{-1}\left(m^{-}\right)=\left(m^{g}\right)^{-1}\left(m^{+}\right)=1$, but the opposite is not true ${ }^{20}$.

Agents with a good health disposition who decide to purchase health care can choose their earnings-consumption pair either on $c=y-m^{-}-T\left(y, m^{-}\right)$or on $c=y-m^{+}-T\left(y, m^{+}\right)$. If on the contrary $m=0$ they choose their earnings-consumption pair on $c=y-T(y, 0)$. Finally, the unskilled ones among them who decide to work full time end up with a pre-tax income equal either to $w^{u}\left(\left(m^{g}\right)^{-1}(0)\right)$ or $w^{u}\left(\left(m^{g}\right)^{-1}\left(m^{-}\right)\right)=w^{u}\left(\left(m^{g}\right)^{-1}\left(m^{+}\right)\right)$(similarly, the skilled ones who work full time obtain a pre-tax income equal either to $w^{s}\left(\left(m^{g}\right)^{-1}(0)\right)$ or $\left.w^{s}\left(\left(m^{g}\right)^{-1}\left(m^{-}\right)\right)=w^{s}\left(\left(m^{g}\right)^{-1}\left(m^{+}\right)\right)\right)$.

Things work similarly for agents with a bad health disposition (except for the fact that spending an amount $m^{-}$in health care does not allow them to reach a good health status and a higher productivity) ${ }^{21}$. Notice also that, at laissez-faire, the difference in consumption between hardworking-poor agents with a bad health disposition and hardworking-poor agents with a good health disposition, if they both decide to purchase health care, is exactly equal to $m^{+}-m^{-}$. That is, even if they have the same marginal productivity, the same concern for health and they put maximal effort into work they might end up facing a considerable difference in their consumption levels. This is exclusively due to their different health disposition.

Let $R_{i}^{*}$ define agent $i$ 's preferences over consumption, earnings and health expenditure. These are derived from the ordinary preferences $R_{i}$ we have defined in the $(c, l, h)$-space, given $w_{i}($.$) and$ $m_{i}($.$) , via the following identity$

$(c, y, m) R_{i}^{*}\left(c^{\prime}, y^{\prime}, m^{\prime}\right) \Leftrightarrow\left(c, \frac{w_{i}(h) l}{w_{i}(h)}, h\right) R_{i}\left(c^{\prime}, \frac{w_{i}\left(h^{\prime}\right) l^{\prime}}{w_{i}\left(h^{\prime}\right)}, h^{\prime}\right)$.

An allocation $z \in Z$ is incentive compatible if and only if no agent envies the bundle of any

\footnotetext{
${ }^{19}$ An agent with a good health disposition might be willing to spend more than necessary to be healthy, even if this does not increase further her productivity or her health, if the tax scheme makes it convenient for her.

${ }^{20}$ In fact, $0=\left(m^{b}\right)^{-1}\left(m^{-}\right) \neq\left(m^{b}\right)^{-1}\left(m^{+}\right)=1$.

${ }^{21}$ Clearly, between two agents with the same health disposition, the budget set of the skilled ones is always bigger with respect to inclusion if compared to that of the unskilled ones. Similarly, between two agents with the same earning ability, the budget set of those with a good health disposition is bigger with respect to inclusion if compared to that of agents with a bad health disposition.
} 
other agent provided that such a bundle is feasible for her: for all $i, j \in N$,

either $\left(c_{i}, y_{i}, m_{i}\right) R_{i}^{*}\left(c_{j}, y_{j}, m_{j}\right)$ or $y_{j}>w_{i}\left(m_{i}^{-1}\left(m_{j}\right)\right)$.

In other words agent $i$ has to receive a bundle that she prefers to the bundle received by agent $j$ unless it is not possible for her to mimic agent $j$. The informational structure of the problem forces us to focus, for any $e \in \mathcal{D}$, on the set of feasible incentive-compatible allocations. Among them, all the allocations that are Pareto undominated are called second-best efficient.

The fact that each agent $i \in N$ is free to choose any point $\left(c_{i}, y_{i}, m_{i}\right)$ maximizing her satisfaction in the budget set modified by a given tax policy $T$ provides us with a convenient way to represent incentive-compatible allocations. Indeed, the allocation resulting from such a choice will necessarily be an envy free allocation. Building on such an intuition, Fleurbaey and Maniquet [17] have proved that any incentive-compatible allocation can be generated by a tax function such that the locus of points

$S(T)=\left\{(c, y, m) \in \mathbb{R}_{+} \times \mathbb{R}_{+} \times M \mid c=y-m-T(y, m)\right\}$,

lies nowhere above the envelope curve of the indifference curves in the $(c, y, m)$-space, and intersects this envelope curve at all points $\left(c_{i}, y_{i}, m_{i}\right)$ for each $i \in N$. An incentive compatible allocation so obtained is feasible if and only if $\sum_{i=1}^{N} T\left(y_{i}, m_{i}\right) \geq 0$.

Notice that, by monotonicity of individual preferences, there is no loss of generality in restricting our attention to tax functions such that, for each $m \in M, y-m-T(y, m)$ is non-decreasing in $y$. By monotonicity of individual preferences we can also say that a rational agent would never choose, for some $m \in M$, a certain consumption-earnings pair $(c, y)$ knowing that, given the tax function, for some $m^{\prime}>m$, she could obtain (with a higher productivity due to a better health status) a consumption-earnings pair $\left(c^{\prime}, y^{\prime}\right)$, with $c<c^{\prime}$ and $y<y^{\prime}$, by working the same amount of time as in $(c, y)$. Let us focus in particular on the part of the budget set modified by the tax function which is attainable for an unskilled agent ${ }^{22}$. With a slight abuse of notation let

$c_{(\alpha, m)}=\alpha w^{b}\left(\left(m^{g}\right)^{-1}(m)\right)-T\left(\alpha w^{b}\left(\left(m^{g}\right)^{-1}(m)\right), m\right)-m$,

denote the amount of consumption, given the tax function $\mathrm{T}$, obtainable by some agent who, for some $m \in M$, choses her earnings in the interval $\left[0, w^{u}\left(\left(m^{g}\right)^{-1}(m)\right)\right]$ namely, $y=\alpha w^{u}\left(\left(m^{g}\right)^{-1}(m)\right.$ with $\alpha \in[0,1]$. This could either be an unskilled agent so that indeed $y=\alpha w^{u}\left(\left(m^{g}\right)^{-1}(0)\right)$, or a skilled agent so that $y=\alpha^{\prime} w^{s}\left(\left(m^{b}\right)^{-1}(0)\right)$ with $\alpha^{\prime}=\frac{\alpha}{\gamma}{ }^{23}$. If, for example, the tax function proposed by the policy maker is such that, for some $\alpha \in[0,1], c_{(\alpha, 0)}<c_{\left(\alpha, m^{-}\right)}$and $c_{(\alpha, 0)}<c_{\left(\alpha, m^{+}\right)}$, then no agent, by monotonicity of individual preferences, will choose from the budget set a bundle such that $m=0$ and $y=\alpha w^{u}(0)$.

We will start by considering tax functions such that for each $\alpha \in[0,1], c_{(\alpha, 0)} \geq c_{\left(\alpha, m^{-}\right)}$and $c_{\left(\alpha, m^{-}\right)} \geq c_{\left(\alpha, m^{+}\right)}{ }^{24}$.

We will assume that, given the tax function $T$, individual preferences are diverse enough so that all the points along the consumption function $y-m-T(y, m)$ are relevant, that is, each

\footnotetext{
${ }^{22}$ We focus on this particular region of the tax function because, as it will be clearer later, this is the relevant region for the evaluation of tax policies.

${ }^{23}$ Indeed, $y=\alpha w^{u}\left(\left(m^{g}\right)^{-1}(0)\right)=\alpha^{\prime} w^{s}\left(\left(m^{b}\right)^{-1}(0)\right)=\alpha^{\prime} \gamma w^{u}\left(\left(m^{b}\right)^{-1}(0)\right)$ which implies $\alpha^{\prime}=\frac{\alpha}{\gamma}$.

${ }^{24}$ The latter inequality rules out situations where an agent with a bad health disposition mimics an agent with a good health disposition.
} 
point of this function hits the indifference curve of at least one agent ${ }^{25}$. In other words $S(T)$ coincides with the envelope of the indifference curves of all agents at the incentive compatible allocation generated by $T$. In these cases $T$ is said to be minimal.

Finally we assume that pre-tax income is not too informative of one's productivity and health expenditure is not too informative of one's health disposition. The idea is that, for any $m \in M$, $y \in\left[0, w^{u}\left(\left(m^{b}\right)^{-1}(m)\right)\right]$, it is impossible to distinguish agents with the lowest earning ability and worst health disposition from agents with better personal circumstances solely looking at their preferences (i.e., at their earned income and their health expenditure).

Assumption 1: for any $i \in N$ there exists $j \in N$ such that $w_{j}()=.w^{u}(),. m_{j}()=.m^{b}($. and $R_{j}^{*}=\left.R_{i}^{*}\right|_{\mathbb{R}_{+} \times\left[0, w^{u}\left(\left(m^{b}\right)^{-1}(m)\right)\right] \times M}$.

Assumption 1 is meant to rule out two unreasonable situations. First, a tax function that, for some $m \in M$, presents unrealistically high tax rates, over some interval $\left[y, y^{\prime}\right]$, only because the policy maker is aware of the fact that only skilled agents would actually decide to pick up their own income in such an interval. Second, tax functions that, for any $y \in \mathbb{R}^{+}$present unrealistically high tax rates, for some $m \in M$, only because the policy maker is aware of the fact that only agents with a good health disposition would actually decide to have their own health expenditure equal to this value.

The first problem we want to tackle is the evaluation of tax reforms. That is, consider any tax function supporting a non (second-best) optimal allocation. Which part of it should be changed first by the policy maker in order to obtain a reform that improves social welfare (according to the specific definition of social welfare we are using)? Which agents should be taxed more and which ones should be taxed less? This question is quite relevant since typically social reforms deal with the choice of a certain alternative belonging to a subset of suboptimal alternatives. We are looking for a criterion that could be used for the comparison of any pair of tax policies, no matter how far from the optimum.

The fact that we are using social preferences of the leximin type turns out to be particularly helpful in answering this question. Indeed, for a given tax policy, we have to find out who is the worst off, according to the $I T($.$) well-being index, at the allocation supported by such a tax$ policy. Once we know that, we also know who should benefit first from an eventual reform. To put it differently, between two different tax policies we will recommend the one that grants a higher well-being level to the worst-off agent.

The next result allows us to spot the worst-off agent at the allocation supported by any minimal tax policy. Let us focus on the subpopulation of unskilled agents with a bad health disposition, $N^{u b}=\left\{i \in N \mid w_{i}=w^{u}(),. m_{i}=m^{b}().\right\}$. Assumption 1 and the fact that $T$ is minimal imply that over $\left[0, w^{u}\left(\left(m^{b}\right)^{-1}(m)\right)\right] \times M$, it is the envelope curve of such agents. The well-being level of the worst off among them is given by

$$
\begin{gathered}
I T^{u b}=\min _{i \in N^{u b}} I T_{i}\left(z_{i}\right)= \\
=\min \left\{t \in \mathbb{R} \mid \exists(l, h) \in[0,1] \times\{0,1\}, t+\bar{w}(h) l-\bar{m}(h)=w^{u}(h) l-m^{b}(h)-T\left(w^{u}(h) l, m^{b}(h)\right)\right\} .
\end{gathered}
$$

It is convenient to represent this expression in the $(c, y, m)$ space.

\footnotetext{
${ }^{25}$ This is quite reasonable for large populations, we are saying that there are agents spread all over the budget set modified by the tax function.
} 


$$
\begin{aligned}
& I T^{u b}=\min \left\{t \in \mathbb{R} \mid \exists(y, m) \in\left[0, w^{u}\left(\left(m^{b}\right)^{-1}(m)\right)\right] \times M,\right. \\
& \left.\quad t+\frac{\bar{w}\left(\left(m^{b}\right)^{-1}(m)\right)}{w^{u}\left(\left(m^{b}\right)^{-1}(m)\right)} y-\bar{m}\left(\left(m^{b}\right)^{-1}(m)\right)=y-m-T(y, m)\right\} .
\end{aligned}
$$

We can rearrange this expression so that we finally obtain

$$
I T^{u b}=\min \left\{c-\frac{\bar{w}\left(\left(m^{b}\right)^{-1}(m)\right)}{w^{u}\left(\left(m^{b}\right)^{-1}(m)\right)} y+\bar{m}\left(\left(m^{b}\right)^{-1}(m)\right) \mid(c, y, m) \in S(T), y \in\left[0, w^{u}\left(\left(m^{b}\right)^{-1}(m)\right)\right]\right\} .
$$

It turns out that this formula allows us to spot the worst-off agent in the entire population. That is, the worst off in the sub-popultation of unskilled agents with a bad health disposition is actually the worst off in the entire population.

Theorem 2: Let $z$ be an incentive-compatible allocation obtainable with the minimal tax policy $T$, then, under Assumption 1,

$$
\min _{i} I T_{i}\left(z_{i}\right)=\min _{(c, y, m) \in S(T),(y, m) \in\left[0, w^{u}\left(\left(m^{b}\right)^{-1}(m)\right)\right] \times M}\left\{c-\frac{\bar{w}\left(\left(m^{b}\right)^{-1}(m)\right)}{w^{u}\left(\left(m^{b}\right)^{-1}(m)\right)} y+\bar{m}\left(\left(m^{b}\right)^{-1}(m)\right)\right\} .
$$

This result is very important because it gives us an easy way to compare two different (minimal) tax policies $T$ and $T^{\prime}$. We just have to apply the previous formula in order to obtain $\min _{i} I T_{i}\left(z_{i}\right)$ and $\min _{i} I T_{i}\left(z_{i}^{\prime}\right)$ where $z$ and $z^{\prime}$ are the incentive compatible allocations supported respectively by $T$ and $T^{\prime}$. If for example

$$
\min _{i} I T_{i}\left(z_{i}^{\prime}\right)>\min _{i} I T_{i}\left(z_{i}\right)
$$

then, by Theorem 1, we know that $z^{\prime}$ is socially preferred to $z$ so that $T^{\prime}$ should be preferred to $T$. This theorem tells us that, in order to obtain an improvement in social welfare, the policy maker needs to focus on a specific region of the budget set modified by the tax function, namely all pairs $(y, m) \in\left[0, w^{u}\left(\left(m^{b}\right)^{-1}(m)\right)\right] \times M$ since the worst off will be in any case an unskilled agent with a bad health disposition. Interestingly this considerably narrows down the scope of the findings of Fleurbaey and Maniquet [19], [20]. They had already shown that when looking for the worst off, at any minimal tax function, one has to focus on the unskilled agents. Our result allows us to focus on a considerably smaller class of agents.

What is also very important about this result is that the deriving comparison criterion does not require much information about the characteristics of the population. The policy maker only needs to know the distribution of $w^{u}(),. w^{s}(),. m^{g}($.$) and m^{b}($.$) (to be able to compute the average$ mappings), but there is no need, for example, to elicit particular information about individual preferences, the computation only depends on the function $T^{26}$. A simple example should clarify this point and show how Theorem 2 practically works. Consider the tax function $T$ such that $T(y, m)=-10+\frac{y-m}{2}$. This tax function grants a basic income equal to 10 to any agent and taxes labor income, after the complete deduction of health expenditure, at a $50 \%$ rate. Let also $m^{-}=6$, $m^{+}=12, w^{u}\left(\left(m^{g}\right)^{-1}(0)\right)=w^{u}\left(\left(m^{b}\right)^{-1}(0)\right)=8, w^{u}\left(\left(m^{g}\right)^{-1}\left(m^{-}\right)\right)=w^{u}\left(\left(m^{b}\right)^{-1}\left(m^{+}\right)\right)=16$, $w^{s}\left(\left(m^{g}\right)^{-1}(0)\right)=w^{s}\left(\left(m^{b}\right)^{-1}(0)\right)=12, w^{s}\left(\left(m^{g}\right)^{-1}\left(m^{-}\right)\right)=w^{s}\left(\left(m^{b}\right)^{-1}\left(m^{+}\right)\right)=24$. To keep things simple let us assume that the number of skilled agents is the same as the number of unskilled agents and that the number of agents with a good health disposition is the same as the number of agents with a bad health disposition. To apply the formula provided in theorem 2 , that is, to find out who is the worst off at the allocation supported by this tax function,

\footnotetext{
${ }^{26} \mathrm{An}$ accurate knowledge of the distribution of individual preferences is necessary only to establish whether a tax policy is feasible. The criterion we propose ranks all feasible and unfeasible tax policies without discrimination.
} 
we just have to compute $\bar{w}($.$) and \bar{m}($.$) . We have \bar{w}\left(\left(m^{g}\right)^{-1}\left(m^{-}\right)\right)=\bar{w}\left(\left(m^{b}\right)^{-1}\left(m^{+}\right)\right)=10$, $\bar{w}\left(\left(m^{g}\right)^{-1}\left(m^{-}\right)\right)=\bar{w}\left(\left(m^{b}\right)^{-1}\left(m^{+}\right)\right)=20$ and $\bar{m}\left(m^{g}\right)^{-1}\left(m^{-}\right)=\bar{m}\left(m^{b}\right)^{-1}\left(m^{+}\right)=9$.

Applying the formula in Theorem 2 amounts to compute

$$
\min _{(y, m) \in\left[0, w^{u}\left(\left(m^{b}\right)^{-1}(m)\right)\right] \times M}\left\{y-m-\frac{y-m}{2}+10-\frac{\bar{w}\left(\left(m^{b}\right)^{-1}(m)\right)}{w^{u}\left(\left(m^{b}\right)^{-1}(m)\right)} y+\bar{m}\left(\left(m^{b}\right)^{-1}(m)\right)\right\} .
$$

It is easy to verify that the worst-off agent is an unskilled agent with a bad health disposition who is working full time and whose health expenditure is equal to $m^{+}$. Her level of well-being is

$$
I T\left(z_{i}\right)=16-12-\frac{16-12}{2}+10-\frac{20}{16} 16+9=1 .
$$

This is somehow striking since the tax scheme in the example treats health expenditure quite generously ( $m$ is fully deductible). Nonetheless such an agent is still the worst off in society and any reform leading to an increase of her consumption should be accepted.

Notice that, the fact that in the above example the worst-off agent is working full time and she is purchasing health care, depends both on the shape of the budget set modified by the tax function and on the shape of the hypothetical budget set we are using to evaluate individual well-being. Notice also that in our example $\bar{w}\left(\left(m^{b}\right)^{-1}\left(m^{+}\right)\right)-\bar{w}\left(\left(m^{b}\right)^{-1}(0)\right)-\bar{m}\left(\left(m^{b}\right)^{-1}\left(m^{+}\right)\right) \geq 0$ (that is, the average increase in productivity deriving from being healthy is higher than the average expenditure necessary to be healthy). This means that the social preferences push toward tax functions that provide more consumption to hardworking-poor agents whose health expenditure is different from zero than hardworking-poor agents whose health expenditure is 0 . This could lead to tax functions that are no longer minimal since they generate a budget set such that choosing a positive level of health expenditure, given a certain amount of labor, always dominates (in terms of consumption) choosing $m=0$.

To such extent, we will consider tax functions such that there exists some $\widehat{\alpha} \in[0,1]$ such that, for each $\alpha \leq \widehat{\alpha}, c_{(\alpha, 0)} \geq c_{\left(\alpha, m^{-}\right)}$and for each $\alpha>\widehat{\alpha}, c_{(\alpha, 0)}<c_{\left(\alpha, m^{-}\right)}{ }^{27}$ (but still, $c_{\left(\alpha, m^{-}\right)} \geq$ $c_{\left(\alpha, m^{+}\right)}$for each $\left.\alpha \in[0,1]\right)$. This clearly means that no agent, skilled or unskilled, will choose a bundle from the part of the budget set modified by the tax function such that $m=0$ and $y \in\left[\widehat{\alpha} w^{u}\left(\left(m^{b}\right)^{-1}(0)\right), w^{u}\left(\left(m^{b}\right)^{-1}(0)\right)\right]$. We still assume that the profile of preferences is rich enough so that there are agents spread all over the remaining parts of the budget set (that is, in those parts $S(T)$ still coincides with the envelope of the indifference curves of all agents at the incentive compatible allocation generated by $T$ ). In these cases $T$ is said to be $\widehat{\alpha}$-minimal. When we deal with $\widehat{\alpha}$-minimal tax schedules it becomes more difficult to find the precise value of $\min _{i} I T_{i}\left(z_{i}\right)$. Nonetheless, in many cases it is possible to spot which region of the budget set should be the object of a welfare improving reform.

Theorem 3: Let $z$ be an incentive-compatible allocation obtainable with the $\widehat{\alpha}$-minimal tax policy $T$ then, under Assumption 1,

$$
\min \left\{c-\frac{\bar{w}\left(\left(m^{b}\right)^{-1}(m)\right)}{w^{u}\left(\left(m^{b}\right)^{-1}(m)\right)} y+\bar{m}\left(\left(m^{b}\right)^{-1}(m)\right) \mid(c, y, m) \in S(T), y \in\left[0, w^{u}\left(\left(m^{b}\right)^{-1}(0)\right)\right]\right\} \leq
$$

\footnotetext{
${ }^{27}$ We could consider situations where there are several intervals over which buying health dominates not buying health, this would just make the computations heavier without adding any value to our results.
} 


$$
\min _{i \in N} I T_{i}\left(z_{i}\right) \leq \widehat{\alpha}\left(w^{u}\left(\left(m^{b}\right)^{-1}(0)\right)-\bar{w}\left(\left(m^{b}\right)^{-1}(0)\right)-T\left(\widehat{\alpha}\left(w^{u}\left(\left(m^{b}\right)^{-1}(0)\right), 0\right) .{ }^{28}\right.\right.
$$

Theorem 3 says that when we deal with tax functions that are only $\widehat{\alpha}$-minimal it is no longer possible to obtain a precise measure of $\min _{i} I T_{i}\left(z_{i}\right)$ but we can only rely on an interval of values. We can still say that the worst off is some unskilled agent with a bad health disposition but we may not be able to locate exactly the part of the budget set modified by the tax function where this agent is located. This happens because no agent would choose certain parts of the budget set.

It is important to stress that this result does not necessarily hinder the possibility of finding which part of the tax policy should be eventually object of a reform. Depending on the parameters of the problem in some cases it is still possible to single out precisely "where" is the worst-off agent. If by a mere observation of the tax function it turns out that

$$
\begin{aligned}
& \min \left\{c-\frac{\bar{w}\left(\left(m^{b}\right)^{-1}(0)\right)}{w^{u}\left(\left(m^{b}\right)^{-1}(0)\right)} y \mid(c, y, m) \in S(T), y \in\left[0, w^{u}\left(\left(m^{b}\right)^{-1}(0)\right)\right], m=0\right\}> \\
& \min \left\{c-\frac{\bar{w}\left(\left(m^{b}\right)^{-1}(0)\right)}{w^{u}\left(\left(m^{b}\right)^{-1}(0)\right)} y+\bar{m}\left(\left(m^{b}\right)^{-1}(0)\right) \mid(c, y, m) \in S(T), y \in\left[0, w^{u}(m)\right], m \neq 0\right\},
\end{aligned}
$$

then the ACEE budget set touches $S(T)$ in some point where agents' health expenditure is positive first. But this part of the budget set still coincides with the envelope of the indifference curves of all agents whose health expenditure is positive so that

$$
\min _{i} I T_{i}\left(z_{i}\right)=\min \left\{c-\frac{\bar{w}\left(\left(m^{b}\right)^{-1}(0)\right)}{w^{u}\left(\left(m^{b}\right)^{-1}(0)\right)} y+\bar{m} \mid(c, y, m) \in S(T), y \in\left[0, w^{u}\left(\left(m^{b}\right)^{-1}(0)\right)\right], m \neq 0\right\} .
$$

Increasing the consumption of such an agent will certainly lead to a social improvement.

If the opposite of (5.1) holds then the worst-off agent cannot be precisely spot because the ACEE budget set touches $S(T)$ in some point where agents' health expenditure is 0 first. This part of the budget set does not coincide with the envelope of the indifference curves of all agents whose health expenditure is 0 . Nonetheless, if

$$
\begin{gathered}
\min \left\{c-\frac{\bar{w}\left(\left(m^{b}\right)^{-1}(0)\right)}{w^{u}\left(\left(m^{b}\right)^{-1}(0)\right)} y+\bar{m} \mid(c, y, m) \in S(T), y \in\left[0, w^{u}\left(\left(m^{b}\right)^{-1}(0)\right)\right], m \neq 0\right\}> \\
\widehat{\alpha}\left(w^{u}\left(\left(m^{b}\right)^{-1}(0)\right)-\bar{w}\left(\left(m^{b}\right)^{-1}(0)\right)\right)-T\left(\widehat{\alpha} w^{u}(0), 0\right),
\end{gathered}
$$

then, by theorem 3 , the worst off will be among the agents who have not purchased health care and whose earnings are within the range $\left[0, \gamma \widehat{\alpha} w^{u}(0)\right]$ so, at least, we can spot the region of the budget set that should be object of reform.

Finally, if none of the previous cases applies then a comparison between two allocation $z$ and $z^{\prime}$ supported by two tax policies $T$ and $T^{\prime}$ is possible if, when we compare the intervals of values within which $\min _{i} I T\left(z_{i}\right)$ and $\min _{i} I T\left(z_{i}^{\prime}\right)$ should be, the lower bound of one of these two intervals dominates the upper bound of the other. Clearly such a criterion might be silent in some applications.

\footnotetext{
${ }^{28}$ Where$$
\widehat{\alpha}\left(w^{u}\left(\left(m^{b}\right)^{-1}(0)\right)\right)-\bar{w}\left(\left(m^{b}\right)^{-1}(0)\right)-T\left(\widehat{\alpha} w^{u}\left(\left(m^{b}\right)^{-1}(0)\right), 0\right)=
$$$$
=\min \left\{y-m-T(y, m)-\frac{\bar{w}\left(\left(m^{b}\right)^{-1}\left(m_{i}\right)\right)}{w^{u}\left(\left(m^{b}\right)^{-1}\left(m_{i}\right)\right)} y+\bar{m}\left(\left(m^{b}\right)^{-1}\left(m_{i}\right)\right) \mid(c, y, m)=\left(c_{(\widehat{\alpha}, 0)}, \widehat{\alpha} w^{u}(0), 0\right)\right\} .
$$ 
The previous results are clearly a useful tool if one wants to rank sub-optimal policies which is typically the situation faced by policy-makers. Nonetheless it is interesting to study the essential features of the optimal policy in order to better understand how our objective of fairness affects redistribution.

Theorem 4: Let $z^{*}$ be an optimal (incentive-compatible) allocation for the ACEE social ordering function. Then, under Assumption 1, $z^{*}$ can be obtained with a tax function $T^{*}$ which, among all feasible tax functions, maximizes $c_{\left(1, m^{+}\right)}$under the constraints that, for some $\alpha^{\prime} \in[0,1]$ :

i) $c_{\left(1, m^{+}\right)}=c_{\left(1, m^{-}\right)}=c_{\left(\alpha^{\prime}, 0\right)}+\bar{w}\left(\left(m^{b}\right)^{-1}\left(m^{+}\right)\right)-\alpha^{\prime} \bar{w}\left(\left(m^{b}\right)^{-1}(0)\right)-\bar{m}\left(\left(m^{b}\right)^{-1}\left(m^{+}\right)\right)$

ii) for $\mathrm{m}=0$ and,

a) $y \geq 0: T^{*}(y, 0) \geq T^{*}\left(w^{u}\left(\left(m^{b}\right)^{-1}(0)\right), 0\right)$

b) $y \leq \alpha^{\prime} w^{u}\left(\left(m^{b}\right)^{-1}(0)\right): \quad y-T^{*}(y, 0) \geq \frac{\bar{w}\left(\left(m^{b}\right)^{-1}(0)\right)}{w^{u}\left(\left(m^{b}\right)^{-1}(0)\right)} y+k^{0}$

with $k^{0}=\alpha^{\prime}\left(w^{u}\left(\left(m^{b}\right)^{-1}(0)\right)-\bar{w}\left(\left(m^{b}\right)^{-1}(0)\right)\right)-T^{*}\left(w^{u}\left(\left(m^{b}\right)^{-1}(0)\right), 0\right)$

iii)for $m=m^{-}$and,

a) $y \geq 0: T^{*}\left(y, m^{-}\right) \geq T^{*}\left(w^{u}\left(\left(m^{g}\right)^{-1}\left(m^{-}\right)\right), m^{-}\right)$

b) $y \leq w^{u}\left(\left(m^{g}\right)^{-1}\left(m^{-}\right)\right): \quad y-T^{*}\left(y, m^{-}\right) \geq \frac{\bar{w}\left(\left(m^{g}\right)^{-1}\left(m^{-}\right)\right)}{w^{u}\left(\left(m^{g}\right)^{-1}\left(m^{-}\right)\right)} y+k^{m^{-}}$

with $k^{m^{-}}=w^{u}\left(\left(m^{b}\right)^{-1}\left(m^{-}\right)-\bar{w}\left(\left(m^{g}\right)^{-1}\left(m^{-}\right)\right)-T^{*}\left(w^{u}\left(\left(m^{g}\right)^{-1}\left(m^{-}\right)\right), m^{-}\right)\right.$

iv) for $m=m^{+}$and,

a) $y \geq 0: T^{*}\left(y, m^{+}\right) \geq T^{*}\left(w^{u}\left(\left(m^{b}\right)^{-1}\left(m^{+}\right)\right), m^{+}\right)$

b) $y \leq w^{u}\left(\left(m^{b}\right)^{-1}\left(m^{+}\right)\right): \quad y-T^{*}\left(y, m^{+}\right) \geq \frac{\bar{w}\left(\left(m^{b}\right)^{-1}\left(m^{+}\right)\right)}{w^{u}\left(\left(m^{b}\right)^{-1}\left(m^{+}\right)\right)} y+k^{m^{+}}$

with $k^{m^{+}}=w^{u}\left(\left(m^{b}\right)^{-1}\left(m^{+}\right)-\bar{w}\left(\left(m^{b}\right)^{-1}\left(m^{+}\right)\right)-T^{*}\left(w^{u}\left(\left(m^{b}\right)^{-1}\left(m^{+}\right)\right), m^{+}\right)\right.$

The theorem says that there is no welfare loss in focusing on tax policies such that $c_{\left(1, m^{+}\right)}$is maximized given the constraints listed in the statement. Its intuition goes as follows. Take any optimal incentive compatible allocation $z^{*}$ and consider an $\alpha$-minimal tax scheme $T$ that supports it. Consider the different sub-populations we can obtain if we look at the health expenditure of agents. Since $z^{*}$ is optimal, the $I T$ level of the worst-off agents across each of these sub-populations must be equal and it coincides with some value $I T^{u}$. Consider now an alternative tax schedule

$$
\widetilde{T}(y, m)=\left\{\begin{array}{l}
\max \left\{T(y, 0),-I T^{u}-\alpha^{\prime}\left(\bar{w}\left(\left(m^{b}\right)^{-1}(0)\right)-w^{u}\left(\left(m^{b}\right)^{-1}(0)\right) \mid y \leq \alpha^{\prime} w^{u}\left(\left(m^{b}\right)^{-1}(0)\right\}\right.\right. \\
\max \left\{T\left(y, m^{-}\right),-I T^{u}-w^{u}\left(\left(m^{g}\right)^{-1}\left(m^{-}\right)\right)+m^{-}-\left(\bar{w}\left(\left(m^{g}\right)^{-1}\left(m^{-}\right)\right)-\bar{m}\left(\left(m^{g}\right)^{-1}\left(m^{-}\right)\right)\right)\right\} \\
\max \left\{T\left(y, m^{+}\right),-I T^{u}-w^{u}\left(\left(m^{b}\right)^{-1}\left(m^{+}\right)\right)+m^{+}-\left(\bar{w}\left(\left(m^{b}\right)^{-1}\left(m^{+}\right)\right)-\bar{m}\left(\left(m^{b}\right)^{-1}\left(m^{+}\right)\right)\right)\right\} .
\end{array}\right.
$$

Such a tax schedule is still feasible because it either cuts subsidies greater than a certain constant or increases taxes that are below a certain threshold. Moreover, it is built in such a way that the constraints listed in theorem 4 are respected and, if we consider the allocation $\widetilde{z}$ supported by $\widetilde{T}, \min _{i} I T(\widetilde{z})=I T^{u}$. If $\widetilde{z}$ did not coincide with $z^{*}$ then it would necessarily generate a strictly positive surplus that could be used to increase the well-being level of the worst-off. This would contradict the fact that $z^{*}$ is optimal. Indeed, the constraints $i i-a$, iii $-a$ and $i v-a$ derive directly from this argument: if the tax function is below this lower bound, then it is possible to find another tax function that satisfies these constraints and that is equivalent in terms of social welfare. 
The focus is on low income earners. It turns out that, among agents whose health expenditure is equal to $\mathrm{m}^{+}$, at the allocation generated by the optimal tax function, the worst off are those working full time. Similarly for agents whose health expenditure is $m^{-}$. For agents whose health expenditure is equal to 0 the worst off are those who work a fraction $\alpha^{\prime}$ of their available working time. Such a value is endogenously determined and it depends on $\bar{w}($.$) and \bar{m}($.$) .$

To sum up, maximizing $\min _{i} I T\left(z_{i}\right)$ implies that the agents we have just listed are those who get the highest subsidy (lowest tax) within each sub-group determined by health expenditure $(i i-a$ $i i i-a$ and $i v-a)$. Equalizing their level of well-being implies that their corrected consumption levels should be optimally equalized $(i)$. In particular, at the optimum, $c_{\left(1, m^{+}\right)}=c_{\left(1, m^{-}\right)}$. This clearly suggests that that a non-uniform rate of taxation of health expenditure is useful at least when it comes to the sub-population of low income earners. This is a consequence of the fact that we are using social preferences aiming at the reduction of inequalities solely due to differences in characteristics for which agents are not responsible. This result does not only go against the common wisdom about commodity taxation but also, as mentioned already, against the findings of Fleurbaey [13]. Taxing the purchase of health care at different rates does affect welfare since agents have to face unequal costs in order to reach a good health status.

This result also completes the findings of Fleurbaey and Maniquet [19], [20]. Here hardworkingpoor agents are still treated with a certain favor. But among them those with the highest subsidy (smallest tax) are those with the highest health expenditure. This clearly pushes toward a reduction of the inequality in the purchasing power (net of health expanditure) of low income earners.

The average marginal tax rate over incomes belonging to the intervals $\left[0, \alpha^{\prime} w^{u}\left(\left(m^{b}\right)^{-1}(0)\right]\right.$, $\left[0, w^{u}\left(\left(m^{g}\right)^{-1}\left(m^{-}\right)\right],\left[0, w^{u}\left(\left(m^{g}\right)^{-1}\left(m^{+}\right)\right]\right.\right.$is non-positive $(i i-a$ and $i i-b, i i i-a$ and $i i i-b, i v-a$ $i v-b)$ so that the income tax is somehow regressive among low income earners. This feature is consistent with the findings of Fleurbaey and Maniquet [20] but also with recent developments of optimal taxation theory (Boadway, Marchand, Pestieau and Racionero [6], Chone and Laroque [8] [9] among others) where the assumption of identical preferences has been dropped. It is important to stress that in these latter contributions the regressivity derives either from the fact that a model that only considers the extensive margin is used or from the fact that certain kinds of individual preferences are given a higher weight. In particular Chone and Laroque [9] (in a recent contribution with a utilitarian setting and heterogeneous preferences) have studied the relation between the social weight curve on one side and the specification of the cardinal utility function and the distribution of preferences on the other. They study the condition under which this relation leads to negative marginal tax rates at the bottom of the income distribution. They also point out that as soon as the the distribution of preferences is independent of that of earning abilities then marginal tax rates are always positive. In contrast, our result (as well as Flaurbaey and Maniquet's result) is mostly due to the axioms that are embedded in the social preferences. These are neutral with respect to individual preferences and actually do not call for any redistribution if all agents were identical in their circumstances. This limits redistribution among low income earners generating some regressivity of the tax scheme (independently of the degree of correlation between earning abilities and individual preferences).

Interestingly, dropping preferences heterogeneity and keeping social preferences of the leximin type would lead to a considerably different conclusion. For example, Boadway and Jacquet [5], using a Rawlsian aggregator, show that the optimal tax scheme always exhibits positive marginal tax rates. Their result is mostly due to the fact that they assume agents having identical 
preferences. In such a framework the maximin aggregator strongly favors agents with the smallest budget set (i.e. unskilled agents) but there is not, like in our setting, a force that limit redistribution among low income earners.

\section{Conclusion}

The main contribution of this paper consists of providing a useful and simple criterion for the comparison of tax policies that have as an argument not only earned income but also health expenditure. Our main result is that, any tax reform should always benefit unskilled individuals with a bad health disposition first. Moreover, among low-income earners, a non-uniform taxation of health is always desirable. This fact derives from the fact that we are aiming at the reduction of inequalities solely due to differences in characteristics for which agents are not responsible. Finally, for any level of health expenditure, the average marginal tax rate is non-positive, this derives from the fact that the axioms used to characterize our social preferences are neutral with respect to individual preferences.

Our exercise relies on social preferences that are singled out by axioms embodying requirements of efficiency and fairness. The only information about individuals that is taken into account by such social preferences is their ordinal non-comparable preferences. No other information about subjective utility is needed for the evaluation of social alternatives. Such social preferences are used here in a second-best framework.

The fact that we only allow for a dichotomous choice of health status and for two types of earning ability and health disposition is mostly meant to simplify the exposition. Theorem 1 would still hold in a more general model allowing for a continuum of health statuses and a continuum of earning ability types. Theorem 2 would also still be adaptable to such a framework. On the other hand it might be more difficult to provide a clear-cut result about the optimal tax scheme. Indeed the fact that agents can only choose between two different health statuses partially inhibits the incentive constraint among agents with different health dispositions. Indeed, with a continuum of values for $h$, an agent with good health disposition who is in good health might mimic an agent with a bad health disposition who is not fully healthy (they might choose the same treatment but this cure completely the former agent and partially the latter). So, to fully understand how taxation may induce people to change their health expenditure compared to what they would have done in first best we need an even more complicated model. This might be object of future research.

\section{APPENDIX}

The following lemma will be useful for the proof of Theorem 1 .

Lemma 1 If a Social Ordering Function satisfies Strong Pareto, Equal Well-being for Equal Preferences and Independence then for all $e \in \mathcal{D}, z, z^{\prime} \in Z$, if there exist $i, j \in N$ such that

$$
z_{i} P z_{i}^{\prime} P z_{j}^{\prime} P z_{j}
$$

and $z_{k}=z_{k}^{\prime}$ for each $k \neq j \neq i$, one has $z^{\prime} \widetilde{P}(e) z$.

Proof of Lemma 1: See proof of Lemma 1 in Fleurbaey and Maniquet [19].

Proof of Theorem 1: Let $\widetilde{R}$ be a social ordering function that satisfies the listed axioms. For the sake of clarity the remaining of the proof is divided in three steps. 
Step 1. Consider two allocations $z$ and $z^{\prime}$ and two different agents $j$ and $k$ such that

$$
I T_{j}\left(z_{j}\right)>I T_{j}\left(z_{j}^{\prime}\right)>I T_{k}\left(z_{k}^{\prime}\right)>I T\left(z_{k}\right)
$$

and for all $i \neq j, k, z_{i}=z_{i}^{\prime}$. We want to prove that $z^{\prime} \widetilde{P}(e) z$. Suppose, by contradiction, that $z \widetilde{R}(e) z^{\prime}$. Introduce two agents $a, b$ such that $w_{a}()=.w_{b}()=.\bar{w}(),. m_{a}()=.m_{b}()=.\bar{m}(),. R_{a}=R_{k}$ and $R_{b}=R_{j}$. Let $e^{\prime}=\left(R, R_{a}, R_{b}, w, w_{a}(),. w_{b}(),. m(),. m_{a}(),. m_{b}().\right)$ and $e^{\prime \prime}=\left(R_{a}, R_{b}, w_{a}(\right.$.$) ,$ $\left.w_{b}(),. m_{a}(),. m_{b}().\right)$. Finally let $z_{a}, z_{b}, z_{a}^{\prime}, z_{b}^{\prime}$ be such that:

(1) $I T_{j}\left(z_{j}^{\prime}\right)>I T_{b}\left(z_{b}^{\prime}\right)=I T_{a}\left(z_{a}\right)>I T_{b}\left(z_{b}\right)=I T_{a}\left(z_{a}^{\prime}\right)>I T_{k}\left(z_{k}^{\prime}\right)$,

(2) $\left.z_{a} \in \max \right|_{R_{a}} B\left(I T_{a}\left(z_{a}\right), w_{a}(),. m_{a}().\right),\left.z_{a}^{\prime} \in \max \right|_{R_{a}} B\left(I T_{a}^{\prime}\left(z_{a}\right), w_{a}(),. m_{a}().\right)$,

(3) $\left.z_{b} \in \max \right|_{R_{b}} B\left(I T_{b}\left(z_{b}\right), w_{b}(),. m_{b}().\right),\left.z_{b}^{\prime} \in \max \right|_{R_{b}} B\left(I T_{b}^{\prime}\left(z_{b}\right), w_{b}(),. m_{b}().\right)$.

By Separation,

$$
\left(z, z_{a}, z_{b}\right) \widetilde{R}\left(e^{\prime}\right)\left(z^{\prime}, z_{a}, z_{b}\right)
$$

By Lemma 1

$$
\left(z_{-k}, z_{k}^{\prime}, z_{a}^{\prime}, z_{b}\right) \widetilde{P}\left(e^{\prime}\right)\left(z, z_{a}, z_{b}\right)
$$

and

By Transitivity,

$$
\left(z_{-\{j, k\}}, z_{j}^{\prime}, z_{k}^{\prime}, z_{a}^{\prime}, z_{b}^{\prime}\right) \widetilde{P}\left(e^{\prime}\right)\left(z_{-k}, z_{k}^{\prime}, z_{a}^{\prime}, z_{b}\right)
$$

$$
\left(z_{-\{j, k\}}, z_{j}^{\prime}, z_{k}^{\prime}, z_{a}^{\prime}, z_{b}^{\prime}\right) \widetilde{P}\left(e^{\prime}\right)\left(z^{\prime}, z_{a}, z_{b}\right)
$$

By Separation

$$
\left(z_{a}^{\prime}, z_{b}^{\prime}\right) \widetilde{P}\left(e^{\prime \prime}\right)\left(z_{a}, z_{b}\right)
$$

Which, by Uniform Circumstances Neutrality, yields the desired contradiction.

Step 2. Consider two allocations $z$ and $z^{\prime}$ and two different agents $j$ and $k$ such that

$$
I T_{k}\left(z_{k}\right)=I T_{j}\left(z_{j}^{\prime}\right)>I T_{k}\left(z_{k}^{\prime}\right)=I T_{j}\left(z_{j}\right)
$$

and for all $i \neq j, k, z_{i}=z_{i}^{\prime}$. We want to prove that $z^{\prime} \widetilde{I}(e) z$. Suppose, by contradiction, that $z \widetilde{P}(e) z^{\prime}$. Introduce two agents $a, b$ such that $w_{a}()=.w_{b}()=.\bar{w}(),. m_{a}()=.m_{b}()=.\bar{m}($.$) ,$ $R_{a}=R_{k}$ and $R_{b}=R_{j}$. Let $e^{\prime}=\left(R, R_{a}, R_{b}, w, w_{a}(),. w_{b}(),. m(),. m_{a}(),. m_{b}().\right)$ and $e^{\prime \prime}=$ $\left(R_{a}, R_{b}, w_{a}(),. w_{b}(),. m_{a}(),. m_{b}().\right)$. Finally let $z_{a}, z_{b}, z_{a}^{\prime}, z_{b}^{\prime}, z_{j}^{\prime \prime}, z_{k}^{\prime \prime}, z_{a}^{\prime \prime}, z_{b}^{\prime \prime}$ be such that:

(1) $I T_{a}\left(z_{a}^{\prime}\right)=I T\left(z_{b}\right)=I T_{k}\left(z_{k}\right), I T_{a}\left(z_{a}\right)=I T_{b}\left(z_{b}^{\prime}\right)=I T_{k}\left(z_{k}^{\prime}\right)$

(2) $z_{k}^{\prime \prime} I_{k} z_{k}, z_{a}^{\prime \prime} I_{a} z_{a}$ and $l_{k}^{\prime \prime}=l_{a}^{\prime \prime}$ $z_{j}^{\prime \prime} I_{j} z_{j}, z_{b}^{\prime \prime} I_{b} z_{b}$ and $l_{j}^{\prime \prime}=l_{b}^{\prime \prime}$

(3) $\left.z_{a} \in \max \right|_{R_{a}} B\left(I T_{a}\left(z_{a}\right), w_{a}(),. m_{a}().\right),\left.z_{a}^{\prime} \in \max \right|_{R_{a}} B\left(I T_{a}^{\prime}\left(z_{a}\right), w_{a}(),. m_{a}().\right)$,

(4) $\left.z_{b} \in \max \right|_{R_{b}} B\left(I T_{b}\left(z_{b}\right), w_{b}(),. m_{b}().\right),\left.z_{b}^{\prime} \in \max \right|_{R_{b}} B\left(I T_{b}^{\prime}\left(z_{b}\right), w_{b}(),. m_{b}().\right)$.

By Separation,

$$
\left(z, z_{a}, z_{b}\right) \widetilde{P}\left(e^{\prime}\right)\left(z^{\prime}, z_{a}, z_{b}\right)
$$

By Pareto Indifference (which is implied by Strong Pareto) and Equal Well-being for Equal Preferences

$$
\left(z_{-k}, z_{a}^{\prime \prime}, z_{k}^{\prime \prime}, z_{b}\right) \widetilde{I}\left(e^{\prime}\right)\left(z, z_{a}, z_{b}\right)
$$


Again, by Pareto Indifference and Equal Well-being for Equal Preferences,

$$
\left(z_{-\{j, k\}}, z_{a}^{\prime \prime}, z_{b}^{\prime \prime}, z_{k}^{\prime \prime}, z_{j}^{\prime \prime}\right) \widetilde{I}\left(e^{\prime}\right)\left(z_{-k}, z_{a}^{\prime \prime}, z_{k}^{\prime \prime}, z_{b}\right) .
$$

By Pareto Indifference,

$$
\left(z_{-\{j, k\}}, z_{k}^{\prime}, z_{j}^{\prime}, z_{a}^{\prime}, z_{b}^{\prime}\right) \widetilde{I}\left(e^{\prime}\right)\left(z_{-\{j, k\}}, z_{a}^{\prime \prime}, z_{b}^{\prime \prime}, z_{k}^{\prime \prime}, z_{j}^{\prime \prime}\right)
$$

By Transitivity,

$$
\left(z_{-\{j, k\}}, z_{k}^{\prime}, z_{j}^{\prime}, z_{a}^{\prime}, z_{b}^{\prime}\right) \widetilde{P}\left(e^{\prime}\right)\left(z^{\prime}, z_{a}, z_{b}\right)
$$

By Separation,

$$
\left(z_{a}^{\prime}, z_{b}^{\prime}\right) \widetilde{P}\left(e^{\prime \prime}\right)\left(z_{a}, z_{b}\right)
$$

The desired contradiction.

Step 3. The rest of the proof derives from standard characterizations of the leximin criterion (Hammond [25]).

Proof of Theorem 2: Consider a minimal tax function $T$ and the incentive-compatible allocation $z$ supported by it. Since $T$ is minimal then $S(T)$ coincides with the envelope curve of the population's indifference surface in the $(c, y, m)$-space at $z$. By Assumption 1, over $\left[0, w^{u}\left(\left(m^{b}\right)^{-1}(m)\right)\right] \times M$, it is the envelope curve of agents from sub-population of unskilled agents with a bad health disposition. Let $N^{u b}=\left\{i \in N \mid w_{i}=w^{u}(),. m_{i}=m^{b}().\right\}$. The minimum value of $I T_{i}\left(z_{i}\right)$ within this sub-population is given by

$$
\begin{gathered}
I T^{u b}=\min _{i \in N^{u b}} I T_{i}\left(z_{i}\right)= \\
=\min \left\{t \in \mathbb{R} \mid \exists(l, h) \in[0,1] \times\{0,1\}, t+\bar{w}(h) l-\bar{m}(h)=w^{u}(h) l-m^{b}(h)-T\left(w^{u}(h) l, m^{b}(h)\right)\right\} .
\end{gathered}
$$

Into the $(c, y, m)$-space the previous expression becomes

$$
\begin{gathered}
I T^{u b}=\min \left\{t \in \mathbb{R} \mid \exists(y, m) \in\left[0, w^{u}\left(\left(m^{b}\right)^{-1}(m)\right)\right] \times M,\right. \\
\left.t+\frac{\bar{w}\left(\left(m^{b}\right)^{-1}(m)\right)}{w^{u}\left(\left(m^{b}\right)^{-1}(m)\right)} y-\bar{m}\left(\left(m^{b}\right)^{-1}(m)\right)=y-m-T(y, m)\right\} \\
=\min \left\{c-\frac{\bar{w}\left(\left(m^{b}\right)^{-1}(m)\right)}{w^{u}\left(\left(m^{b}\right)^{-1}(m)\right)} y+\bar{m}\left(\left(m^{b}\right)^{-1}(m)\right) \mid(c, y, m) \in S(T), y \in\left[0, w^{u}\left(\left(m^{b}\right)^{-1}(m)\right)\right]\right\} .
\end{gathered}
$$

We need to prove that this is indeed the well-being level of the worst-off agent is society. Let $N^{u g}=\left\{i \in N \mid w_{i}=w^{u}(),. m_{i}=m^{g}().\right\}$. Following the argument we have used for $I T^{u b}$ we can prove that the minimum value of $I T_{i}\left(z_{i}\right)$ within this sub-population is given by

$$
\begin{gathered}
I T^{u g}=\min _{i \in N^{u g}} I T_{i}\left(z_{i}\right)= \\
\min \left\{c-\frac{\bar{w}\left(\left(m^{g}\right)^{-1}(m)\right)}{w^{u}\left(\left(m^{g}\right)^{-1}(m)\right)} y+\bar{m}\left(\left(m^{g}\right)^{-1}(m)\right) \mid(c, y, m) \in S(T), y \in\left[0, w^{u}\left(\left(m^{g}\right)^{-1}(m)\right)\right]\right\} .
\end{gathered}
$$

We will first prove that $I T^{u b} \leq I T^{u g}$. Assume by contradiction that $I T^{u b}>I T^{u g}$. By definition of $I T^{u g}$ there exists $\left(y^{\prime}, m^{\prime}\right) \in\left[0, w^{u}\left(\left(m^{g}\right)^{-1}(m)\right)\right] \times M$ such that

$$
y^{\prime}-m^{\prime}-T\left(y^{\prime}, m^{\prime}\right)=I T^{u g}+\frac{\bar{w}\left(\left(m^{g}\right)^{-1}\left(m^{\prime}\right)\right)}{w^{u}\left(\left(m^{g}\right)^{-1}\left(m^{\prime}\right)\right)} y^{\prime}-\bar{m}\left(\left(m^{g}\right)^{-1}\left(m^{\prime}\right)\right) .
$$


By assumption

$$
y^{\prime}-m^{\prime}-T\left(y^{\prime}, m^{\prime}\right)<I T^{u b}+\frac{\bar{w}\left(\left(m^{g}\right)^{-1}\left(m^{\prime}\right)\right)}{w^{u}\left(\left(m^{g}\right)^{-1}\left(m^{\prime}\right)\right)} y^{\prime}-\bar{m}\left(\left(m^{g}\right)^{-1}\left(m^{\prime}\right)\right) .
$$

From the definition of $I T^{u b}$ it follows that, for all $m \in M$ and for all $y \in\left[0, w^{u}\left(\left(m^{b}\right)^{-1}(m)\right)\right]$

$$
I T^{u b}+\frac{\bar{w}\left(\left(m^{b}\right)^{-1}(m)\right)}{w^{u}\left(\left(m^{b}\right)^{-1}(m)\right)} y-\bar{m}\left(\left(m^{b}\right)^{-1}(m)\right) \leq y-m-T(y, m) .
$$

Consider now, $m^{\prime \prime} \in M$ such that

$$
\frac{\bar{w}\left(\left(m^{g}\right)^{-1}\left(m^{\prime}\right)\right)}{w^{u}\left(\left(m^{g}\right)^{-1}\left(m^{\prime}\right)\right)} y^{\prime}-\bar{m}\left(\left(m^{g}\right)^{-1}\left(m^{\prime}\right)\right)=\frac{\bar{w}\left(\left(m^{b}\right)^{-1}\left(m^{\prime \prime}\right)\right)}{w^{u}\left(\left(m^{b}\right)^{-1}\left(m^{\prime \prime}\right)\right)} y^{\prime}-\bar{m}\left(\left(m^{b}\right)^{-1}\left(m^{\prime \prime}\right)\right) .
$$

Clearly $m^{\prime \prime} \geq m^{\prime}$, moreover from equations 7.1 and 7.2

$$
I T^{u b}+\frac{\bar{w}\left(\left(m^{b}\right)^{-1}\left(m^{\prime \prime}\right)\right)}{w^{u}\left(\left(m^{b}\right)^{-1}\left(m^{\prime \prime}\right)\right)} y^{\prime}-\bar{m}\left(\left(m^{b}\right)^{-1}\left(m^{\prime \prime}\right)\right) \leq y^{\prime}-m^{\prime \prime}-T\left(y^{\prime}, m^{\prime \prime}\right),
$$

so that

$$
y^{\prime}-m^{\prime}-T\left(y^{\prime}, m^{\prime \prime}\right)<y^{\prime}-m^{\prime \prime}-T\left(y^{\prime}, m^{\prime \prime}\right),
$$

which contradicts the fact that $T$ is minimal.

Let $N^{s b}=\left\{i \in N \mid w_{i}=w^{s}(),. m_{i}=m^{b}().\right\}$. The minimum value of $\operatorname{IT}_{i}\left(z_{i}\right)$ within this sub-population is given by

$$
I T^{s b}=\min _{i \in N^{s b}} I T_{i}\left(z_{i}\right)=
$$

$$
\min \left\{c-\frac{\bar{w}\left(\left(m^{b}\right)^{-1}(m)\right)}{w^{s}\left(\left(m^{b}\right)^{-1}(m)\right)} y+\bar{m}\left(\left(m^{b}\right)^{-1}(m)\right) \mid(c, y, m) \in S(T), y \in\left[0, w^{s}\left(\left(m^{b}\right)^{-1}(m)\right)\right]\right\} .
$$

We now want to prove that $I T^{u b} \leq I T^{s b}$. Assume by contradiction that $I T^{u b}>I T^{s b}$. By definition of $I T^{s b}$ there exists $\left(y^{\prime}, m^{\prime}\right) \in\left[0, w^{s}\left(\left(m^{b}\right)^{-1}\left(m^{\prime}\right)\right)\right] \times M$ and some $\alpha^{\prime} \in[0,1]$ such that

$$
y^{\prime}-m^{\prime}-T\left(y^{\prime}, m^{\prime}\right)=I T^{s b}+\frac{\bar{w}\left(\left(m^{b}\right)^{-1}\left(m^{\prime}\right)\right)}{w^{s}\left(\left(m^{b}\right)^{-1}\left(m^{\prime}\right)\right)} y^{\prime}-\bar{m}\left(\left(m^{b}\right)^{-1}\left(m^{\prime}\right)\right)
$$

By assumption,

$$
y^{\prime}-m^{\prime}-T\left(y^{\prime}, m^{\prime}\right)<I T^{u b}+\frac{\bar{w}\left(\left(m^{b}\right)^{-1}\left(m^{\prime}\right)\right)}{w^{s}\left(\left(m^{b}\right)^{-1}\left(m^{\prime}\right)\right)} y^{\prime}-\bar{m}\left(\left(m^{b}\right)^{-1}\left(m^{\prime}\right)\right)
$$

From the definition of $I T^{u b}$ it follows that, for all $m \in M$ and all $y \in\left[0, w^{u}\left(\left(m^{b}\right)^{-1}(m)\right)\right]$

$$
I T^{u b}+\frac{\bar{w}\left(\left(m^{b}\right)^{-1}(m)\right)}{w^{u}\left(\left(m^{b}\right)^{-1}(m)\right)} y-\bar{m}\left(\left(m^{b}\right)^{-1}(m)\right) \leq y-m-T(y, m)
$$

In particular, if we let $m=m^{\prime}$ and $y^{\prime \prime}=\frac{w^{u}\left(m^{b}\right)^{-1}\left(m^{\prime}\right)}{w^{s}\left(m^{b}\right)^{-1}\left(m^{\prime}\right)} y^{\prime}$ (so that, by construction, $y^{\prime \prime}<y^{\prime}$ and $\left.y^{\prime \prime} \leq w^{u}\left(m^{b}\right)^{-1}\left(m^{\prime}\right)\right)$ we obtain

$$
I T^{u b}+\frac{\bar{w}\left(\left(m^{b}\right)^{-1}\left(m^{\prime}\right)\right)}{w^{s}\left(\left(m^{b}\right)^{-1}\left(m^{\prime}\right)\right)} y^{\prime \prime}-\bar{m}\left(\left(m^{b}\right)^{-1}\left(m^{\prime}\right)\right) \leq y^{\prime \prime}-m^{\prime}-T\left(y^{\prime \prime}, m^{\prime}\right)
$$

This entails

$$
y^{\prime}-m^{\prime}-T\left(y^{\prime}, m^{\prime}\right)<y^{\prime \prime}-m^{\prime}-T\left(y^{\prime \prime}, m^{\prime}\right)
$$


which contradicts the fact that, for each $m \in M, y-m-T(y, m)$ is non-decreasing in $y$. Let finally $N^{s g}=\left\{i \in N \mid w_{i}=w^{s}(),. m_{i}=m^{g}().\right\}$. Using the same reasoning as above it also possible to prove that both

$$
I T^{s b} \leq I T^{s g}
$$

and

$$
I T^{u g} \leq I T^{s g}
$$

So that finally, by transitivity, we also have

$$
I T^{u b} \leq I T^{s g}
$$

which concludes the proof.

Proof of Theorem 3 Let ucs $\left(\left(c_{i}, y_{i}, m_{i}\right), w_{i}(),. R_{i}^{*}\right)$ denote the closed upper contour set for an unskilled agent with a bad health disposition and with preferences $R_{i}^{*}$ at the bundle $z_{i}=\left(c_{i}, y_{i}, m_{i}\right)$ :

$$
\begin{aligned}
& u c s\left(\left(c_{i}, y_{i}, m_{i}\right), w^{u}(.),\left(m^{b}\right)^{-1}(.), R_{i}^{*}\right)= \\
& \quad=\left\{(c, y, m) \in \mathbb{R}_{+} \times\left[0, w_{i}^{u}\left(\left(m^{b}\right)^{-1}\left(m_{i}\right)\right)\right] \times M \mid(c, y, m) R_{i}^{*}\left(c_{i}, y_{i}, m_{i}\right)\right\} .
\end{aligned}
$$

By definition, for the agents belonging to this subpopulation:

$$
\begin{gathered}
I T^{u b}=\min _{i \in N^{u b}} I T_{i}\left(z_{i}\right)= \\
=\min \left\{c-\frac{\bar{w}\left(\left(m^{b}\right)^{-1}\left(m_{i}\right)\right)}{w^{u}\left(\left(m^{b}\right)^{-1}\left(m_{i}\right)\right)} y+\bar{m}\left(\left(m^{b}\right)^{-1}\left(m_{i}\right)\right) \mid(c, y, m) \in u c s\left(\left(c_{i}, y_{i}, m_{i}\right), w^{u}(.),\left(m^{b}\right)^{-1}(.), R_{i}^{*}\right)\right\} .
\end{gathered}
$$

Consider now the point $\left(c_{(\widehat{\alpha}, 0)}, \widehat{\alpha} w^{u}(0), 0\right)$. The value of the $I T($.$) at such a point is given by$

$$
\begin{gathered}
\min \left\{c-\frac{\bar{w}\left(\left(m^{b}\right)^{-1}\left(m_{i}\right)\right)}{w^{u}\left(\left(m^{b}\right)^{-1}\left(m_{i}\right)\right)} y+\bar{m}\left(\left(m^{b}\right)^{-1}\left(m_{i}\right)\right) \mid(c, y, m)=\left(c_{(\widehat{\alpha}, 0)}, \widehat{\alpha} w^{u}(0), 0\right)\right\}= \\
\min \left\{y-m-T(y, m)-\frac{\bar{w}\left(\left(m^{b}\right)^{-1}\left(m_{i}\right)\right)}{w^{u}\left(\left(m^{b}\right)^{-1}\left(m_{i}\right)\right)} y+\bar{m}\left(\left(m^{b}\right)^{-1}\left(m_{i}\right)\right) \mid(c, y, m)=\left(c_{(\widehat{\alpha}, 0)}, \widehat{\alpha} w^{u}(0), 0\right)\right\}= \\
=\widehat{\alpha}\left(w^{u}\left(\left(m^{b}\right)^{-1}(0)\right)\right)-\bar{w}\left(\left(m^{b}\right)^{-1}(0)\right)-T\left(\widehat{\alpha} w^{u}\left(\left(m^{b}\right)^{-1}(0)\right), 0\right) .
\end{gathered}
$$

Since, for each $i \in N,\left(c_{i}, y_{i}, m_{i}\right) \in u c s\left(\left(c_{i}, y_{i}, m_{i}\right)\right)$ then, necessarily,

$$
\min _{i \in N} I T_{i}\left(z_{i}\right) \leq \widehat{\alpha}\left(w^{u}\left(\left(m^{b}\right)^{-1}(0)\right)\right)-\bar{w}\left(\left(m^{b}\right)^{-1}(0)\right)-T\left(\widehat{\alpha} w^{u}\left(\left(m^{b}\right)^{-1}(0)\right), 0\right) .
$$

On the other hand, from the proof of Theorem 2,

$$
\min _{i \in N} I T_{i}\left(z_{i}\right)=\min _{i \in N^{u b}} I T\left(z_{i}\right) .
$$

Finally, the fact that, by definition, $S(T)$ lies nowhere above the envelope curve of the indifference curves in the $(c, y, m)$-space so that

$$
\min \left\{c-\frac{\bar{w}\left(\left(m^{b}\right)^{-1}(m)\right)}{w^{u}\left(\left(m^{b}\right)^{-1}(m)\right)} y+\bar{m}\left(\left(m^{b}\right)^{-1}(m)\right) \mid(c, y, m) \in S(T), y \in\left[0, w^{u}\left(\left(m^{b}\right)^{-1}(0)\right)\right]\right\} \leq I T^{u b}
$$

concludes the proof.

Proof of Theorem 4: Let $z^{*}$ be an optimal allocation and $T^{*}$ an $\alpha^{\prime}$-minimal tax schedule that supports it. From, the proof of Theorem 2

$$
\min _{i \in N} I T_{i}\left(z_{i}^{*}\right)=\min _{i: i \in N^{u b}} I T\left(z_{i}^{*}\right)=I T^{u b} .
$$


Consider now the tax policy $\widetilde{T}(y, m)$ built from $T^{*}(y, m)$ by cutting, within each class of agents determined by health expenditure, all the subsidies greater than a certain constant or increasing taxes that are below a certain threshold.

So, if $m=0$ and $y \in\left[0, \alpha^{\prime} w^{u}\left(m^{b}\right)^{-1}(0)\right]$,

$$
\widetilde{T}(y, 0)=\max \left\{T^{*}(y, 0),-I T^{u b}-\alpha^{\prime}\left(\bar{w}\left(\left(m^{b}\right)^{-1}(0)\right)-w^{u}\left(\left(m^{b}\right)^{-1}(0)\right)\right\} .\right.
$$

If $m=0$ and $y \in\left[\alpha^{\prime} w^{u}\left(m^{b}\right)^{-1}(0), w^{u}\left(m^{b}\right)^{-1}(0)\right]$,

$$
\widetilde{T}(y, 0)=-I T^{u b}-\alpha^{\prime} \bar{w}\left(\left(m^{b}\right)^{-1}(0)\right)+y .
$$

If $m=0$ and $y \geq w^{u}\left(m^{b}\right)^{-1}(0)$,

$$
\widetilde{T}(y, 0)=\max \left\{T^{*}(y, 0),-I T^{u b}-\alpha^{\prime}\left(\bar{w}\left(\left(m^{b}\right)^{-1}(0)\right)-w^{u}\left(\left(m^{b}\right)^{-1}(0)\right)\right\} .\right.
$$

If $m=m^{-}$,

$\widetilde{T}\left(y, m^{-}\right)=\max \left\{T^{*}\left(y, m^{-}\right),-I T^{u b}+w^{u}\left(\left(m^{g}\right)^{-1}\left(m^{-}\right)\right)-m^{-}-\left(\bar{w}\left(\left(m^{g}\right)^{-1}\left(m^{-}\right)\right)-\bar{m}\left(\left(m^{g}\right)^{-1}\left(m^{-}\right)\right)\right)\right\}$.

If $m=m^{+}$,

$\widetilde{T}\left(y, m^{+}\right)=\max \left\{T^{*}\left(y, m^{+}\right),-I T^{u b}+w^{u}\left(\left(m^{b}\right)^{-1}\left(m^{+}\right)\right)-m^{+}-\left(\bar{w}\left(\left(m^{b}\right)^{-1}\left(m^{+}\right)\right)-\bar{m}\left(\left(m^{g}\right)^{-1}\left(m^{+}\right)\right)\right)\right\}$.

By construction, $\widetilde{T}$ it is still feasible and no individual is expected to earn an income in the interval $\left[\alpha^{\prime} w^{u}\left(m^{b}\right)^{-1}(0), w^{u}\left(m^{b}\right)^{-1}(0)\right]$. Let $\widetilde{z}$ be the allocation decentralized by $\widetilde{T}($.$) . A reasoning$ similar to the one used in the proof of Theorem 3 and the fact that, under $\widetilde{T}($.$) , no agent will$ choose $m=0$ and $y \in\left[\alpha^{\prime} w^{u}\left(m^{b}\right)^{-1}(0), w^{u}\left(m^{b}\right)^{-1}(0)\right]$ yield

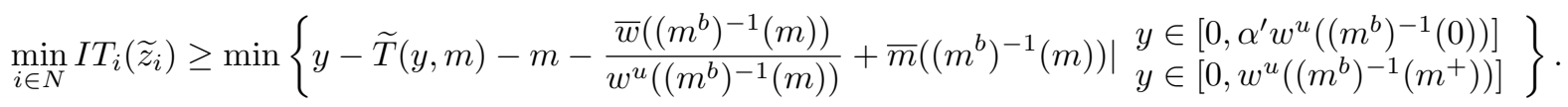

The right hand side of the previous inequality can be rewritten as

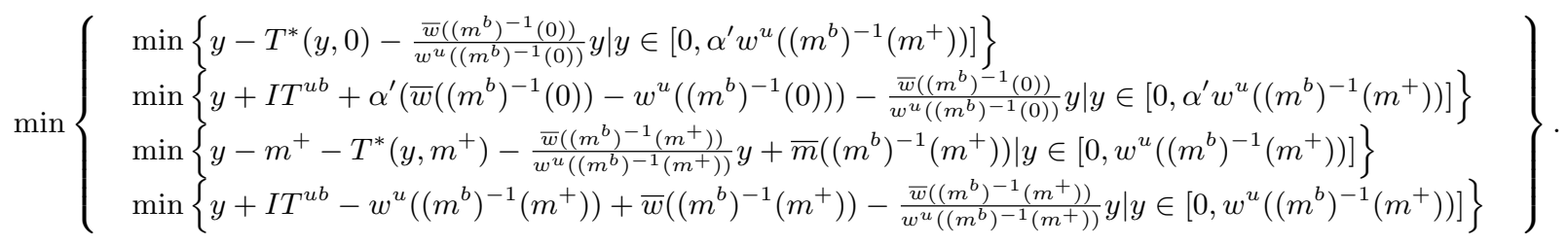

This yields:

$$
\min \left\{\begin{array}{l}
\alpha^{\prime}\left(w^{u}\left(\left(m^{b}\right)^{-1}(0)\right)-\bar{w}\left(\left(m^{b}\right)^{-1}(0)\right)\right)-T\left(\alpha^{\prime} w^{u}\left(\left(m^{b}\right)^{-1}(0)\right), 0\right) \\
I T^{u b} \\
I T^{u b} \\
I T^{u b}
\end{array}\right\} .
$$

From Theorem 3,

so that

$$
I T^{u b} \leq \alpha^{\prime}\left(w^{u}\left(\left(m^{b}\right)^{-1}(0)\right)-\bar{w}\left(\left(m^{b}\right)^{-1}(0)\right)\right)-T\left(\alpha^{\prime} w^{u}\left(\left(m^{b}\right)^{-1}(0)\right), 0\right),
$$

$$
\min _{i \in N} I T_{i}\left(\widetilde{z}_{i}\right) \geq I T^{u b}
$$


Notice that $\min _{i \in N} I T_{i}\left(\widetilde{z}_{i}\right)>I T^{u b}$ would contradict the optimality of $z^{*}$ so that finally

$$
\min _{i \in N} I T_{i}\left(\widetilde{z}_{i}\right)=I T^{u b}
$$

Namely, the lowest well-being level at $\widetilde{z}$ is the same as the lowest well-being level at $z^{*}$. If $z^{*}$ cannot be decentralized by $\widetilde{T}$ then the surplus created by the tax cut can be redistributed across all the agents. This would generate a new allocation that Pareto dominates $z^{*}$ contradicting the fact that it is optimal.

Given the way we have constructed $\widetilde{T}$ it also follows that:

(a) for $m=0$ and

$y \geq 0$,

$$
\widetilde{T}(y, 0) \geq-I T^{u b}-\alpha^{\prime}\left(\bar{w}\left(\left(m^{b}\right)^{-1}(0)\right)-w^{u}\left(\left(m^{g}\right)^{-1}(0)\right)\right),
$$

$y \leq \alpha^{\prime} w^{u}\left(\left(m^{b}\right)^{-1}(0)\right), \quad y-\widetilde{T}(y, 0) \geq I T^{u b}+\frac{\bar{w}\left(\left(m^{b}\right)^{-1}(0)\right)}{w^{u}\left(\left(m^{b}\right)^{-1}(0)\right)} y$.

so, from the previous two equations it follows that, for $y \leq \alpha^{\prime} w^{u}\left(\left(m^{b}\right)^{-1}(0)\right)$

$$
-I T^{u b}-\alpha^{\prime}\left(\bar{w}\left(\left(m^{b}\right)^{-1}(0)\right)-w^{u}\left(\left(m^{b}\right)^{-1}(0)\right)\right) \leq \widetilde{T}(y, 0) \leq-I T^{u b}+y-\frac{\bar{w}\left(\left(m^{b}\right)^{-1}(0)\right)}{w^{u}\left(\left(m^{b}\right)^{-1}(0)\right)} y .
$$

If we set $y=\alpha^{\prime} w^{u}\left(\left(m^{b}\right)^{-1}(0)\right)$, the upper and the lower bound of the inequality expressed in 7.3 coincide so that we obtain

$$
\widetilde{T}\left(\alpha^{\prime} w_{N}^{u}\left(\left(m^{b}\right)^{-1}(0)\right), 0\right)=-I T^{u b}-\alpha^{\prime}\left(\bar{w}\left(\left(m^{b}\right)^{-1}(0)\right)-w^{u}\left(\left(m^{b}\right)^{-1}(0)\right)\right) .
$$

If we plug 7.4 into the two equations in (a) we obtain

(a') for $m=0$ and

$y \geq 0, \quad \widetilde{T}(y, 0) \geq \widetilde{T}\left(\alpha^{\prime} w^{u}\left(\left(m^{b}\right)^{-1}(0)\right), 0\right)$,

$y \leq \alpha^{\prime} w^{u}(0), y-\widetilde{T}(y, 0) \geq \frac{\bar{w}\left(\left(m^{b}\right)^{-1}(0)\right)}{w^{u}\left(\left(m^{b}\right)^{-1}(0)\right)} y-\widetilde{T}\left(\alpha^{\prime} w^{u}\left(\left(m^{b}\right)^{-1}(0)\right), 0\right)-\alpha^{\prime}\left(\bar{w}\left(\left(m^{b}\right)^{-1}(0)\right)-w^{u}\left(\left(m^{b}\right)^{-1}(0)\right)\right)$.

Again, from the way $\widetilde{T}($.$) has been constructed it follows that$

(b) for $m=m^{+}$and

$y \geq 0, \quad \widetilde{T}\left(y, m^{+}\right) \geq-I T^{u b}-\left(\bar{w}\left(\left(m^{b}\right)^{-1}\left(m^{+}\right)\right)-w^{u}\left(\left(m^{b}\right)^{-1}\left(m^{+}\right)\right)+m^{+}-\bar{m}\left(\left(m^{b}\right)^{-1}\left(m^{+}\right)\right)\right)$,

$y \leq w^{u}\left(\left(m^{b}\right)^{-1}\left(m^{+}\right)\right), y-\widetilde{T}\left(y, m^{+}\right)-m^{+}-\frac{\bar{w}\left(\left(m^{b}\right)^{-1}\left(m^{+}\right)\right)}{w^{u}\left(\left(m^{b}\right)^{-1}\left(m^{+}\right)\right)} y+\bar{m}\left(\left(m^{b}\right)^{-1}\left(m^{+}\right)\right) \geq I T^{u b}$.

Hence, for $y \leq w^{u}\left(\left(m^{b}\right)^{-1}\left(m^{+}\right)\right)$

$$
\begin{gathered}
-I T^{u b}-\left(\bar{w}\left(\left(m^{b}\right)^{-1}\left(m^{+}\right)\right)-w^{u}\left(\left(m^{b}\right)^{-1}\left(m^{+}\right)\right)+m^{+}-\bar{m}\left(\left(m^{b}\right)^{-1}\left(m^{+}\right)\right)\right) \leq \widetilde{T}\left(y, m^{+}\right) \leq \\
\leq-I T^{u b}+y-m^{+}-\frac{\bar{w}\left(\left(m^{b}\right)^{-1}\left(m^{+}\right)\right)}{w^{u}\left(\left(m^{b}\right)^{-1}\left(m^{+}\right)\right)} y+\bar{m}\left(\left(m^{b}\right)^{-1}\left(m^{+}\right)\right) .
\end{gathered}
$$

Again, by setting $y=w^{u}\left(\left(m^{b}\right)^{-1}\left(m^{+}\right)\right)$, from 7.5 we obtain that

$$
\widetilde{T}\left(w^{u}\left(\left(m^{b}\right)^{-1}\left(m^{+}\right)\right), m^{+}\right)=-I T^{u b}-\left(\bar{w}\left(\left(m^{b}\right)^{-1}\left(m^{+}\right)\right)-w^{u}\left(\left(m^{b}\right)^{-1}\left(m^{+}\right)\right)+m^{+}-\bar{m}\left(\left(m^{b}\right)^{-1}\left(m^{+}\right)\right)\right) \text {. }
$$

If we plug 7.6 into the two equations in (b) we obtain

(b') for $m=m^{+}$and 
$y \geq 0, \quad \widetilde{T}\left(y, m^{+}\right) \geq \widetilde{T}\left(w^{u}\left(\left(m^{b}\right)^{-1}\left(m^{+}\right)\right), m^{+}\right)$,

$y \leq w^{u}\left(\left(m^{b}\right)^{-1}\left(m^{+}\right)\right), y-\widetilde{T}\left(y, m^{+}\right) \geq \frac{\bar{w}\left(\left(m^{b}\right)^{-1}\left(m^{+}\right)\right)}{w^{u}\left(\left(m^{b}\right)^{-1}\left(m^{+}\right)\right)} y-\widetilde{T}\left(w^{u}\left(\left(m^{b}\right)^{-1}\left(m^{+}\right)\right), m^{+}\right)-\left(\bar{w}\left(\left(m^{b}\right)^{-1}\left(m^{+}\right)\right)-\right.$ $\left.w^{u}\left(\left(m^{b}\right)^{-1}\left(m^{+}\right)\right)\right)$.

In a similar fashion, it is possible to prove that

$\widetilde{T}\left(w^{u}\left(\left(m^{g}\right)^{-1}\left(m^{-}\right)\right), m^{-}\right)=-I T^{u b}-\left(\bar{w}\left(\left(m^{g}\right)^{-1}\left(m^{-}\right)\right)-w^{u}\left(\left(m^{g}\right)^{-1}\left(m^{-}\right)\right)+m^{-}-\bar{m}\left(\left(m^{g}\right)^{-1}\left(m^{-}\right)\right)\right)$.

and

(c') for $m=m^{-}$and

$y \geq 0, \widetilde{T}\left(y, m^{-}\right) \geq \widetilde{T}\left(w^{u}\left(\left(m^{g}\right)^{-1}\left(m^{-}\right)\right), m^{-}\right)$,

$y \leq w^{u}\left(\left(m^{g}\right)^{-1}\left(m^{-}\right)\right), y-\widetilde{T}\left(y, m^{-}\right) \geq \frac{\bar{w}\left(\left(m^{g}\right)^{-1}\left(m^{-}\right)\right)}{w^{u}\left(\left(m^{g}\right)^{-1}\left(m^{-}\right)\right)} y-\widetilde{T}\left(w^{u}\left(\left(m^{g}\right)^{-1}\left(m^{-}\right)\right), m^{-}\right)-\left(\bar{w}\left(\left(m^{g}\right)^{-1}\left(m^{-}\right)\right)-\right.$ $\left.w^{u}\left(\left(m^{g}\right)^{-1}\left(m^{-}\right)\right)\right)$.

Finally, from 7.4

$I T^{u b}=\alpha^{\prime} w^{u}\left(\left(m^{b}\right)^{-1}(0)\right)-\widetilde{T}\left(\alpha^{\prime} w_{N}^{u}\left(\left(m^{b}\right)^{-1}(0)\right), 0\right)-\alpha^{\prime} \bar{w}\left(\left(m^{b}\right)^{-1}(0)\right)=c_{\left(\alpha^{\prime}, 0\right)}-\alpha^{\prime} \bar{w}\left(\left(m^{b}\right)^{-1}(0)\right)$,

from 7.6,

$I T^{u b}=w^{u}\left(\left(m^{b}\right)^{-1}\left(m^{+}\right)\right)-m^{+}-\widetilde{T}\left(w\left(\left(m^{b}\right)^{-1}\left(m^{+}\right)\right), m^{+}\right)-\bar{w}\left(\left(m^{b}\right)^{-1}\left(m^{+}\right)\right)+\bar{m}\left(\left(m^{b}\right)^{-1}\left(m^{+}\right)\right)=$ $c_{\left(1, m^{+}\right)}-\bar{w}\left(\left(m^{b}\right)^{-1}\left(m^{+}\right)\right)+\bar{m}\left(\left(m^{b}\right)^{-1}\left(m^{+}\right)\right)$,

and from 7.7

$I T^{u b}=w^{u}\left(\left(m^{g}\right)^{-1}\left(m^{-}\right)\right)-m^{-}-\widetilde{T}\left(w\left(\left(m^{g}\right)^{-1}\left(m^{-}\right)\right), m^{-}\right)-\bar{w}\left(\left(m^{g}\right)^{-1}\left(m^{-}\right)\right)+\bar{m}\left(\left(m^{g}\right)^{-1}\left(m^{-}\right)\right)=$ $c_{\left(1, m^{-}\right)}-\bar{w}\left(\left(m^{g}\right)^{-1}\left(m^{-}\right)\right)+\bar{m}\left(\left(m^{g}\right)^{-1}\left(m^{-}\right)\right)$,

So, since $\bar{w}\left(\left(m^{g}\right)^{-1}\left(m^{-}\right)\right)=\bar{w}\left(\left(m^{b}\right)^{-1}\left(m^{+}\right)\right)$and $\bar{m}\left(\left(m^{g}\right)^{-1}\left(m^{-}\right)\right)=\bar{m}\left(\left(m^{b}\right)^{-1}\left(m^{+}\right)\right)$, it follows that

$$
c_{\left(1, m^{+}\right)}=c_{\left(1, m^{-}\right)}=c_{\left(\alpha^{\prime}, 0\right)}+\bar{w}\left(\left(m^{b}\right)^{-1}\left(m^{+}\right)\right)-\alpha^{\prime} \bar{w}\left(\left(m^{b}\right)^{-1}(0)\right)-\bar{m}\left(\left(m^{b}\right)^{-1}\left(m^{+}\right)\right) .
$$

\section{REFERENCES}

[1] K. J. Arrow Social Choice and Individual Values. Wiley, New York (1951).

[2] C. d'Aspremont, L.Gevers, Equity and the Informational Basis of Collective Choice, Review of Economic Studies 44(1977) 199-209.

[3] A. B. Atkinson, J.E. Stiglitz, The design of tax structure: direct versus indirect taxation, Journal of Public Economics, 6(1976) 55-75.

[4] A. Blomqvist, H. Horn, Public Health Insurance and Optimal Income Taxation, Journal of Public Economics, 24(1984) 352-371.

[5] R. Boadway, L. Jacquet, Optimal Marginal and Average Income Taxation under Maximin, Journal of Economic Theory, 143(2008) 425-441.

[6] R. Boadway, M. Marchand, P. Pestieau, M. Racionero, Optimal Redistribution with Heterogeneous Preferences for Leisure, Journal of Public Economic Theory, 4(2002), 475-498. 
[7] R. Boadway, P. Pestieau, Indirect Taxation and Redistribution: The Scope of the Atkinson-Stiglitz Theorem, in Richard Arnott, Bruce Greenwald, Ravi Kanbur and Barry Nalebuff (eds.), Economics for an Imperfect World: Essays in Honor of Joseph E. Stiglitz, MIT Press (2003).

[8] P. Choné, G. Laroque, Optimal incentives for labor force participation, Journal of Public Economics, 89(2005) 395-425.

[9] P. Choné, G. Laroque, Negative Marginal Tax Rates and Heterogeneity, American Economic Review, 100(2010) $2532 Đ 47$.

[10] H. Cremer, P. Pestieau, Redistributive Taxation and Social Insurance, International Tax and Public Finance, 3(1996) 281-295.

[11] K. Christensen, N. V. Holm, M. Mcgue, L. Corder, J. W. Vaupel, A Danish Population-Based Twin Study on General Health in the Elderly, Journal of Aging and Health, 11(1999), 49-64.

[12] M. Fleurbaey, Health, Wealth and Fairness, Journal of Public Economic Theory, 7(2005) 253-284.

[13] M. Fleurbaey, Is commodity taxation unfair?, Journal of Public Economics 90(2006) 1765-1787.

[14] M. Fleurbaey, Fairness, responsibility and welfare. Oxford University Press, New York (2008).

[15] M. Fleurbaey, F. Maniquet, Utilitarianism versus fairness in welfare economics, in M. Salles and J. A. Weymark (eds), Justice, Political Liberalism and Utilitarianism: Themes from Harsanyi and Rawls, Cambridge U. Press, forthcoming.

[16] M. Fleurbaey, F. Maniquet, Compensation and responsibility, in K.J. Arrow, A.K. Sen and K. Suzumura (Eds), Handbook of Social Choice and Welfare V. II, North-Holland, forthcoming.

[17] M. Fleurbaey, F. Maniquet, A Theory of Fairness and Social Welfare, Cambridge University Press (2011).

[18] M. Fleurbaey, F. Maniquet, Fair social orderings when agents have unequal production skills, Social Choice and Welfare 24(2005) 93-127.

[19] M. Fleurbaey, F. Maniquet, Fair Income Tax, Review of Economic Studies, 73(2006), 55-83.

[20] M. Fleurbaey, F. Maniquet, Help the low-skilled or let the hardworking thrive? A study of fairness in optimal income taxation, Journal of Public Economic Theory 9(2007) 467-500.

[21] M. Fleurbaey, E. Schokkaert,Unfair inequalities in health and health care, Journal of Health Economics 28 (2009) 73-90.

[22] M. Flaurbaey, K. Suzumura, and K. Tadenuma, Arrovian Aggregation in Economic Environments: How Much Should We Know About Indifference Surfaces?, Journal of Economic Theory 124(2005), pages 22-44.

[23] M. Grossman, L. Benham, Health, Hours and Wages, M. Perlman (ed.), The Economics of Health and Medical Care. Macmillan and Co., London (1974).

[24] D. Henriett, J.C. Rochet, Is Public Health Insurance an Appropriate Instrument for Redistribution?, Annales d'economie et de statistique, 83-84(2006) 61-88.

[25] P.J. Hammond, Equity, Arrow's conditions and Rawls' difference principle, Econometrica 44(1976) 793-804.

[26] B. Hansson, The independence condition in the theory of social choice. Theory and Decision 4(1973), $25 \nsupseteq 49$.

[27] W. Jack, Redistributing to the sick: How should health expenditures be integrated into the tax system?, mimeo.

[28] L. Jacquet, D. Van de gaer, A Comparison of Optimal Tax Policies when Compensation or Responsibility Matter, Journal of Public Economics (forthcoming).

[29] H. Luft, The Impact of Poor Health on Earnings. Review of Economics and Statistics, 57 (1975), 43-57.

[30] M.G. Marmot, G. Davey Smith, S. Stansfeld, C. Patel, F. North, J. Head, I. White, E. Brunner, A. Feeney, Health inequalities among British civil servants: the Whitehall II study, Lancet 337(1991) 1387-1393.

[31] S. Mushkin, Health as an Investment, Journal of Political Economy 70(1962), 129-157.

[32] E. Pazner, Equity, nonfeasible alternatives and social choice: A reconsideration of the concept of social welfare. In J.J. Laffont (Ed.), Aggregation and Revelation of Preferences. North-Holland, Amsterdam (1979).

[33] J. Poterba, Government Intervention in the Markets for Education and Health Care: How and Why. NBER working paper 4916 (1994).

[34] D.D. Reid, G.Z. Brett, P.J.S. Hamilton, R.J. Jarrett, H. Keen, G. Rose, Cardio-respiratory disease and diabetes among middle-aged male civil servants: a study of screening and intervention. Lancet 303(1974) 469-473.

[35] J.C. Rochet, Incentives, Redistribution and Social Insurance, Geneva Papers on Risk and Insurance Theory, 16(1991), 143-165.

[36] J.E. Roemer, Equality of opportunity. Harvard University Press, Cambridge (1998).

[37] E. Saez, Optimal income transfer programs: intensive versus extensive labor supply responses, Quarterly Journal of Economics, 117(2002), 1039-1073.

[38] W. Thomson, Consistent Allocation Rules, mimeo 2004.

[39] G. Valletta, A Fair solution to the compensation problem, Social Choice and Welfare 32(2009) 455-478. 